\title{
Disponibilidade de ferro, digestibilidade de proteína e teor de $\beta$-caroteno em formulados alternativos de baixo custo para alimentação enteral de idosos
}

\author{
Iron availability, protein digestibility and beta-carotene amount in alternative formulated of low cost for elderly
}

\author{
Karina de Oliveira CALHEIROS ${ }^{1}$, Solange Guidolin CANNIATTI-BRAZACA²*
}

\begin{abstract}
Resumo
O objetivo geral deste trabalho foi elaborar formulados alternativos à base de mistura de alimentos convencionais provenientes da cesta básica distribuída por entidades do município de Piracicaba-SP, entre outros alimentos, com o intuito de suplementar a alimentação enteral de idosos. Os alimentos utilizados para elaboração dos formulados foram fubá, óleo de soja, arroz, feijão, macarrão, sardinha, leite em pó, amido de milho, ovos, proteína texturizada de soja, couve-manteiga e cenoura. Foram realizadas análises químicas: composição centesimal, digestibilidade de proteína, determinação do mineral ferro, diálise de ferro in vitro, determinação de $\beta$-caroteno e fatores antinutricionais, assim como fenólicos totais e ácido fítico; e análise de custos dos formulados. Os resultados obtidos foram submetidos às análises estatísticas empregando o teste de Tukey e análises de regressão. Concluiu-se com este estudo que os formulados líquidos apresentaram os melhores resultados nutricionais e viabilidade econômica. Dentre estes, podem-se eleger duas alternativas. O formulado F3 se destacou na disponibilidade de ferro, quantidades de $\beta$-caroteno e digestibilidade. O formulado F4 se destacou na distribuição do valor calórico total de macronutrientes. Os formulados contribuem com percentual médio de $20 \%$ de adequação para idosos, quando ingeridas duas porções de $250 \mathrm{~mL} /$ dia de formulados líquidos ou em pó.

Palavras-chave: idosos; formulados; disponibilidade de ferro; digestibilidade, $\beta$-caroteno; alimentação enteral.
\end{abstract}

\begin{abstract}
The aim of this study was to develop alternative formulas for elderly enteral feeding using conventional foods from food staples distributed in the city of Piracicaba-SP. The foods used in the formulas were: corn meal, soybean oil, rice, beans, pasta, sardine, powder milk, corn starch, eggs, textured soy protein, cabbage, and carrot. Chemical analyses (centesimal composition, protein digestibility, iron determination, iron dialyses in vitro, $\beta$-carotene determination, anti-nutritional factors - tannins, and phytate) and cost analyses were carried out. The results were analyzed statistically using the Tukey test and regression. Liquid formulas presented better nutritional and economical viability. According to the elderly clinical needs, two alternatives are suggested among the liquid formulas tested. Formula F3 for its iron availability, quantity of $\beta$-carotene, and digestibility and formula F4 for is for the total calorie distribution of macronutrients as well as for having a higher number of calories. The formulas achieved $20 \%$ adequacy when two servings of $250 \mathrm{~mL} /$ day (powder or liquid) were ingested.

Keywords: elderly; formulas; iron availability; digestibility; $\beta$-carotene; enteral feeding.
\end{abstract}

\section{Introdução}

Uma parcela significativa da população que possui restrição alimentar é constituída por idosos, a qual vem se intensificando no contexto atual de envelhecimento populacional brasileiro. A cada ano, 650 mil indivíduos são incorporados à população de idosos no Brasil (INSTITUTO BRASILEIRO DE GEOGRAFIA E ESTATÍSTICA, 2002).

Em maior evidência do que os demais grupos etários, o atendimento à população idosa apresenta extraordinário desafio, especialmente pela fragilidade do indivíduo, carência e tendência em contrair doenças crônicas e incapacitantes (LIMA; LIMA; FREITAS, 2004). Apesar da demanda crescente por serviços sociais e de saúde no cuidado direcionado aos idosos, a família continua sendo a instituição que cumpre o papel central neste contexto (UCHÔA; FIRMO; LIMA-COSTA, 2002).
O que se tem observado é um crescente aumento no uso da nutrição enteral (NE) em terapia domiciliar, principalmente o uso de formulados artesanais preparados com base em alimentos in natura, os quais são de difícil acesso às famílias de baixa renda, bem como na adequação às necessidades nutricionais dos seus idosos (ARAUJO; MENEZES, 2006; DOMENE; GALEAZZI, 1997).

Os alimentos provenientes da cesta básica podem contribuir significativamente para a segurança alimentar. No caso o arroz e feijão são alimentos relativamente baratos, nutritivos e abundantes no País. Com a combinação desses alimentos, se obtêm quase todos os aminoácidos necessários para o nosso organismo. Além disso, são fonte de amido, vitaminas do complexo B, fibras e minerais. Alguns pesquisadores afirmam

Recebido para publicação em 30/7/2008

Aceito para publicação em 27/10/2009 (003727)

'Ciência e Tecnologia de Alimentos, Departamento de Agroindústria, Alimentos e Nutrição da Escola Superior de Agricultura "Luiz de Queiroz" - ESALQ, Universidade de São Paulo - USP, E-mail: kaoka2@ig.com.br

2 Departamento de Agroindústria, Alimentos e Nutrição da Escola Superior de Agricultura "Luiz de Queiroz" - ESALQ, Universidade de São Paulo -USP, CEP 13418-900, Piracicaba -SP, E-mail: sgcbraza@esalq.usp.br

${ }^{*}$ A quem a correspondencia deve ser enviada 
que essa combinação pode prevenir câncer na cavidade bucal, faringe ou laringe (EMPRESA..., 2008).

O objetivo desse estudo é elaborar formulados alternativos à base de mistura de alimentos convencionais provenientes da cesta básica, distribuída por entidades do município de Piracicaba - SP, entre outros alimentos, voltados para a alimentação enteral suplementar do idoso. Para isso foram estabelecidas as quantidades necessárias e as combinações alternativas de cada alimento previamente selecionado para a composição dos formulados, elaborados conforme as necessidades nutricionais dos idosos e das especificações técnicas referentes aos suplementos já disponíveis no mercado; apontadas as principais características nutricionais e a viabilidade econômica, associadas aos formulados elaborados; estabelecidos os diferentes tipos de formulados alternativos elaborados a partir da mesma matriz de alimentos selecionados.

\section{Material e Métodos}

\subsection{Matéria-prima}

As matérias-primas utilizadas foram fubá, óleo de soja, arroz, feijão, macarrão, sardinha, leite em pó, amido de milho, ovo, proteína texturizada de soja, couve-manteiga e cenoura. Os alimentos foram adquiridos no comércio de Piracicaba - SP, tendo alguns sido doados pela prefeitura do município de Piracicaba, através do programa municipal de cesta básica. Os alimentos foram escolhidos por seu fácil acesso à população alvo do estudo.

A população de referência para este estudo foram pessoas com faixa etária de sessenta anos ou mais, que vivem em situação econômica desfavorecida. Essa população é atendida pelo programa de atendimento domiciliar - PAD - do Sistema Único de Saúde do município de Piracicaba, SP, e tem dependências físicas e nutricionais, sendo $20 \%$ dessa população, alimentada com nutrição enteral.

\subsection{Elaborações dos formulados}

Para elaborarem-se os formulados, foi realizado um levantamento dos principais suplementos comercializados para idosos. Com base na composição dos suplementos comerciais, fez-se a média dos macronutrientes, considerando: carboidratos $50 \%$, proteínas $16 \%$ e lipídios $34 \%$ e, a partir desses dados, elaboraram-se seis novos formulados nutricionais, em pó e no estado líquido, com porções de alimentos que correspondam à mesma composição de macronutrientes. A Tabela 1 apresenta a composição de cada tipo de formulado.

\subsection{Preparação das amostras}

As amostras foram preparadas no Laboratório de Bromatologia da ESALQ/USP, simulando ambiente domiciliar. Os ingredientes foram padronizados segundo a Tabela de Medida Caseira (MOREIRA, 2002; PINHEIRO et al., 2002) e aplicaram-se as boas práticas de fabricação, no que diz respeito à higiene dos alimentos. Os que necessitaram de cozimento foram preparados em panelas comuns de alumínio e, logo em seguida, misturados aos demais, em liquidificador modelo Skymsen eletro, até a obtenção de uma mistura homogênea, peneirada em seguida (tela de nylon plana, abertura de $1 \mathrm{~mm}$ de diâmetro).

$\mathrm{O}$ arroz foi retirado da embalagem, escolhido e depois lavado em água corrente; em seguida, foi submetido à cocção em panela de alumínio, acrescentando-se água fervente na proporção de 3:1(água: arroz), cozinhando por 15 minutos para o cozimento total.

O feijão foi escolhido, lavado e deixado em maceração por 24 horas sob refrigeração; em seguida, foi desprezada a água do remolho e o feijão, colocado em panela de pressão doméstica por 45 minutos, utilizando-se a proporção 3:1, água e feijão.

O macarrão foi retirado da embalagem e colocado para cocção em panela de alumínio, com água em ebulição, por aproximadamente 20 minutos.

O amido de milho foi diluído em água filtrada, na proporção 3:1 (água: amido de milho), e depois colocado em panela de alumínio para cocção, por aproximadamente 6 minutos.

Os ovos foram colocados em panela comum de alumínio com água fria e aquecidos até a temperatura de ebulição, em que ficaram por 10 minutos; em seguida, foram retirados da água e as cascas removidas.

O fubá foi diluído em água filtrada, na proporção 3:1 (água:fubá), e colocado em panela de alumínio para cocção, por aproximadamente 10 minutos.

As folhas da couve-manteiga foram lavadas, desprezandose as impróprias para o uso e alguns talos, depois cortadas em um tamanho mínimo de aproximadamente $0,5 \mathrm{~cm}$ e colocadas à cocção em panela de alumínio, sem tampa, com água em ebulição, por aproximadamente 15 minutos, na proporção 1:5 (couve:água).

As cenouras foram lavadas, descascadas e cortadas em tiras com tamanho de aproximadamente $1 \mathrm{~cm}$, depois colocadas para cocção em água em ebulição, com panela aberta, na proporção 1:5 (cenoura:água), por 20 minutos.

Os demais ingredientes que não necessitaram de cocção tiveram higienizadas as suas embalagens, foram retirados delas e utilizados em seguida. Após a mistura, o formulado foi preparado de dois modos diferentes (Figura 1).

\subsection{Formulados}

Após o preparo dos alimentos, foram elaborados os formulados, totalizando 12, sendo 6 na forma líquida e 6 na forma de pó conforme demonstrado na Tabela 2 .

\subsection{Composição centesimal}

As análises químicas de teor de matéria seca, proteína bruta, extrato etéreo, fibra alimentar e de cinzas foram realizadas de acordo com a metodologia indicada pela Association of Official Analytical Chemists - AOAC (2006). 
Tabela 1. Composição dos macronutrientes dos formulados testados.

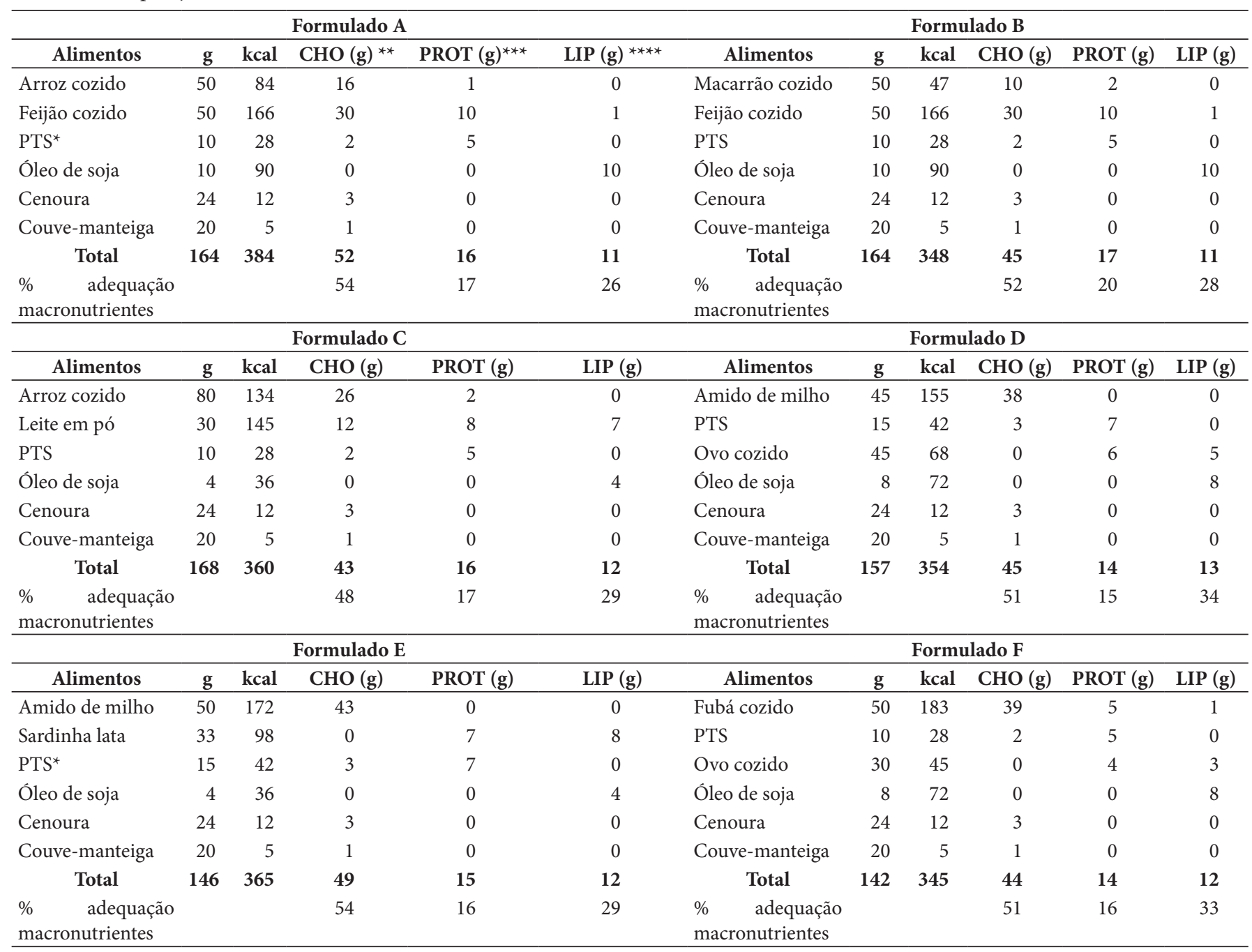

${ }^{\star}$ PTS-Proteína texturizada de soja. ${ }^{* *}$ CHO-Carboidratos Totais. ${ }^{* * *}$ PROT-Proteínas. ${ }^{* * *}$ LIP-Lipídios.

\subsection{Diálise de ferro in vitro}

A análise da diálise de ferro in vitro foi realizada segundo método proposto por Whittaker, Fox e Forbes (1989).

\subsection{Determinação de ferro}

O mineral ferro foi determinado pelo método de Sarruge e Haag (1974) e realizou-se a leitura em espectrofotômetro de absorção atômica a $248,3 \mathrm{~nm}$.

\subsection{Digestibilidade in vitro de proteína}

As análises de digestibilidade de proteína foram realizadas através do método proposto por Akeson e Stahmann (1964).

\subsection{Fenólicos totais}

O teor de fenólicos totais foi determinado pelo método de Swain e Hillis (1959). A leitura foi realizada na absorbância, em $660 \mathrm{~nm}$.

\subsection{0 Ácido fítico}

Os teores de ácido fítico nas amostras foram determinados segundo o método descrito por Grynspan e Cheryan (1989).

\subsection{Determinação do $\beta$-caroteno}

As determinações das concentrações de $\beta$-caroteno nas misturas foram baseadas no procedimento de MinazziRodriguez e Penteado (1989).

\subsection{Análises dos custos dos formulados}

Para a análise do custo, foi realizada pesquisa de mercado no mês de abril de 2008 em estabelecimentos comerciais da cidade de Piracicaba, SP, e de instituições de pesquisas, como o Instituto de Economia Agrícola (2008), a fim de se obterem os valores dos formulados elaborados, para posterior comparação aos produtos industrializados similares. 


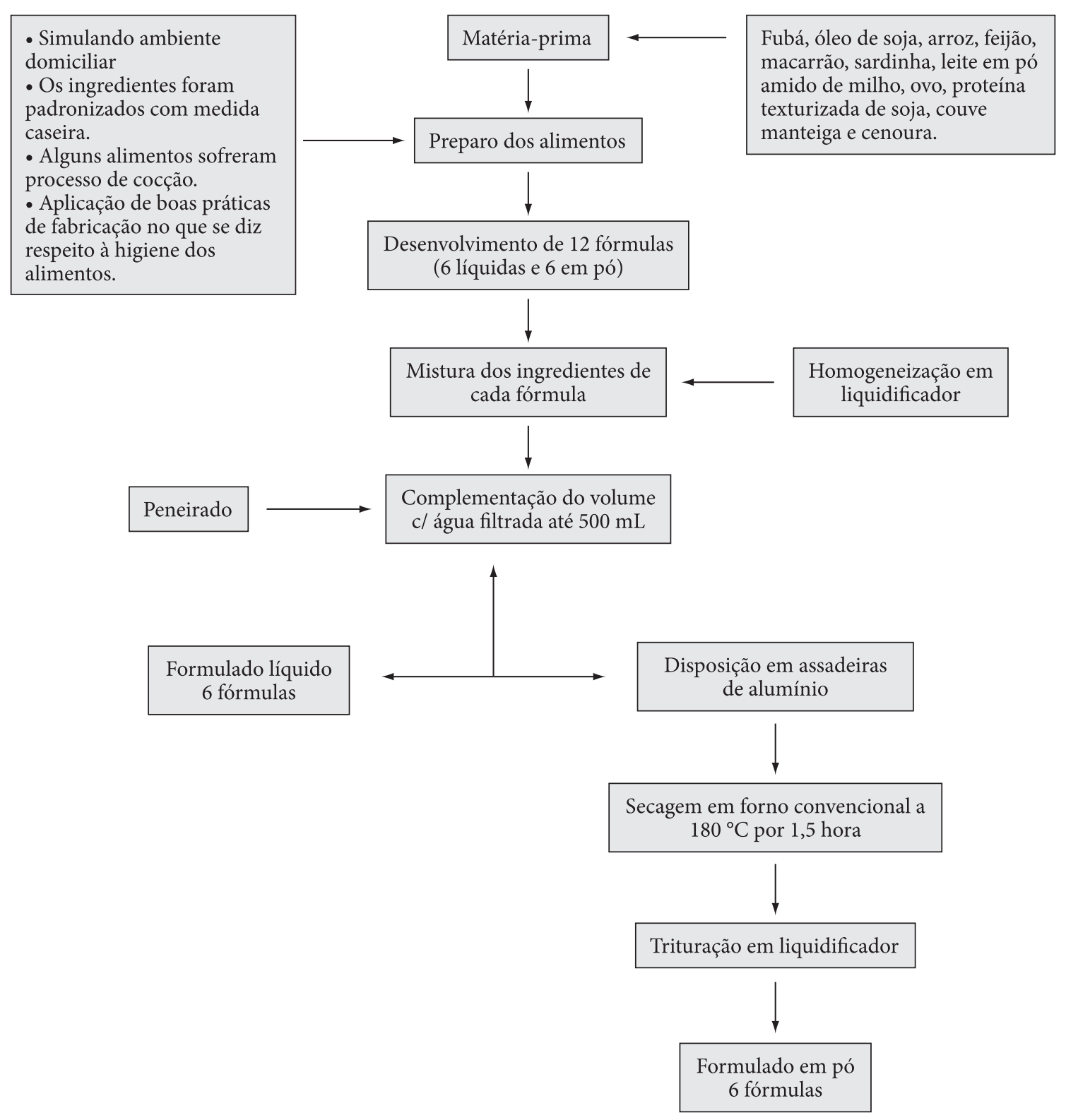

Figura 1. Fluxograma de elaboração de formulados líquidos e em pó.

O custo calculado foi o aparente, referente apenas à matériaprima empregada, pois não foram levados em consideração os custos indiretos de mão de obra, energia elétrica, gás e outros.

\subsection{Delineamento estatístico}

O delineamento estatístico utilizado foi inteiramente ao acaso, para a comparação das médias pelo teste $F$. As diferenças estatísticas obtidas nos diferentes tratamentos foram realizadas segundo o Método de Tukey (PIMENTEL-GOMES, 1982). Foi aplicado o software Statistical Analysis System Institute (STATISTICAL..., 1996) para a análise dos dados. E, para o teste de regressão, foi utilizado o programa Microsoft Office Excel (MICROSOFT, 2003).

\section{Resultados e discussão}

Os resultados das análises estão representados nas Figuras 2 e 3 e nas Tabelas 3 a 11. Para efeito de comparação de alguns resultados obtidos referentes aos formulados desenvolvidos, foram utilizados os valores descritos na literatura para cada componente do formulado em questão, de modo a representar a proporção pré-definida de cada amostra.

\subsection{Composição centesimal}

A composição centesimal dos formulados foi determinada com o objetivo de caracterizar os componentes utilizados no estudo. Os resultados obtidos nas análises estão apresentados na Tabela 3. 
Tabela 2. Composição dos formulados líquidos e em pó.

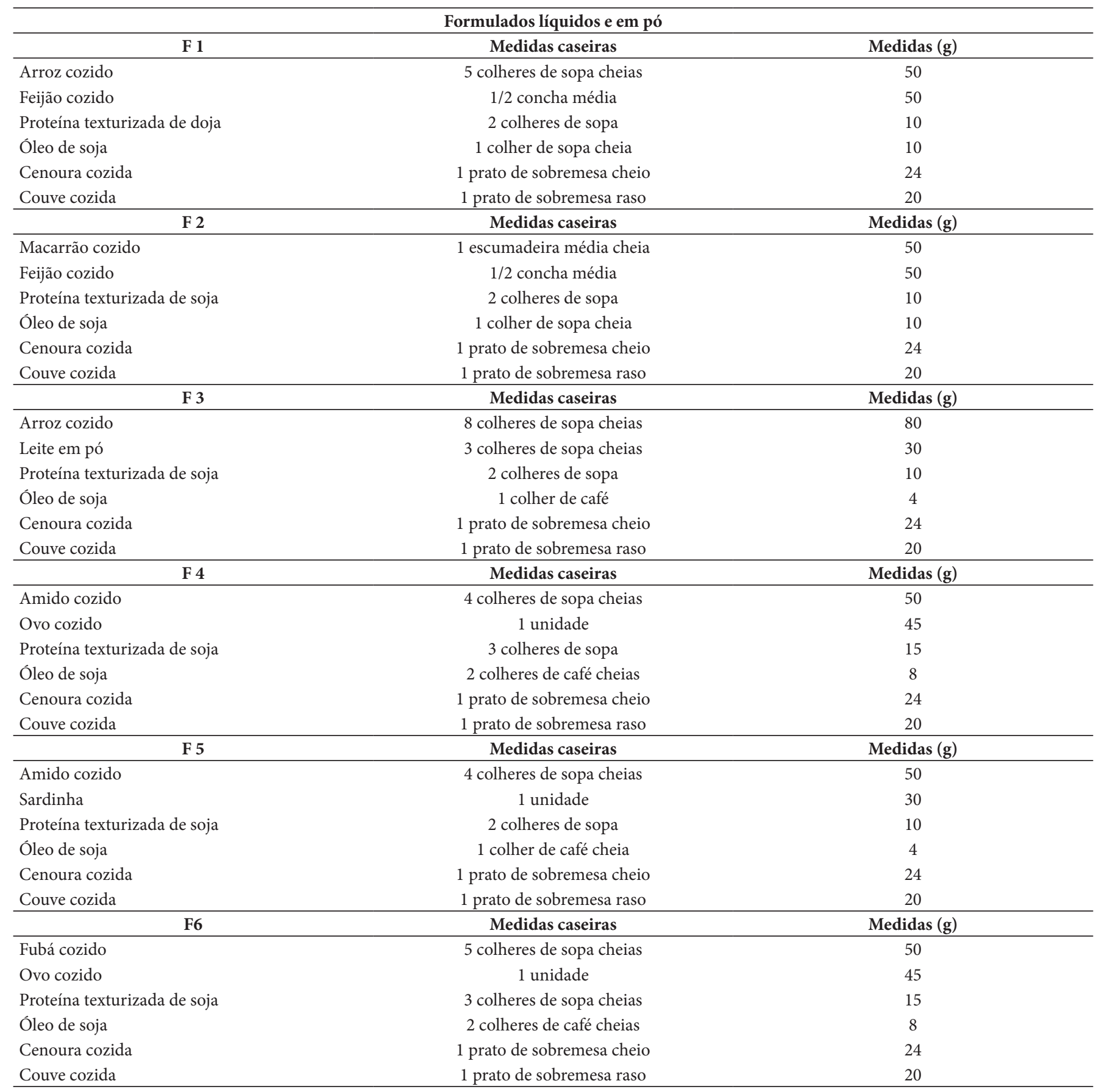

Os formulados líquidos apresentaram teores de carboidratos entre 20,0 e 60,1 g. $100 \mathrm{~g}^{-1}$, sendo o maior teor para F5 e o menor para F1. No entanto, os formulados em pó apresentaram teores entre 23,9 e 34,2 g. $100 \mathrm{~g}^{-1}$, sendo o maior teor para F1 e o menor para F3.

O formulado F5 (líquido) foi o que mais se aproximou dos dados da literatura (UNIVERSIDADE DE SÃO PAULO, 2004), apresentando $62 \mathrm{~g}$ de carboidratos. $100 \mathrm{~g}^{-1}$. Ao analisar os outros formulados, verificou-se discrepância com os valores da literatura nos diferentes formulados, tanto para o procedimento líquido como para o em pó, que pode ser justificada pelos métodos aplicados e composição dos formulados, principalmente os desidratados, que não têm essa especificação na tabela utilizada. Os valores obtidos foram a soma dos obtidos na tabela de composição (resultado por diferença), o que também pode ocasionar variação.

Ao analisar os teores de proteínas dos formulados, em comparação com os teores da literatura, verificaram-se teores 
Tabela 3. Teores de proteínas, lipídios, cinzas, fibras e carboidratos, em g.100 g ${ }^{-1}$, em diferentes formulações, expressos na base seca.

\begin{tabular}{|c|c|c|c|c|c|c|c|}
\hline & & F1 & $\mathrm{F} 2$ & F3 & F4 & F5 & F6 \\
\hline \multirow[t]{2}{*}{ Proteínas } & $\mathrm{L}$ & $25,12+1,1^{1 \mathrm{~B} 2}$ & $30,76+2,1^{\mathrm{A}}$ & $23,82+1,1^{\mathrm{B}}$ & $23,64+2,7^{\mathrm{B}}$ & $18,76+1,0^{\mathrm{C}}$ & $27,50+1,5^{\mathrm{BA}}$ \\
\hline & $\mathrm{P}$ & $25,50+0,9^{\mathrm{B}}$ & $25,50+0,9^{\mathrm{B}}$ & $25,10+0,2^{\mathrm{B}}$ & $16,43+0,2^{\mathrm{D}}$ & $19,21+0,7^{\mathrm{C}}$ & $20,36+0,4^{\mathrm{C}}$ \\
\hline \multirow[t]{2}{*}{ Lipídios } & $\mathrm{L}$ & $18,95+0,2^{\mathrm{A}}$ & $19,97+0,3^{\mathrm{A}}$ & $12,81+0,9^{\mathrm{C}}$ & $13,98+1,0^{\mathrm{C}}$ & $12,22+1,1^{\mathrm{C}}$ & $16,34+0,5^{\mathrm{B}}$ \\
\hline & $\mathrm{P}$ & $8,20+0,6^{\mathrm{D}}$ & $8,60+0,0^{\mathrm{D}}$ & $16,00+0,0^{\mathrm{A}}$ & $9,24+0,6^{\mathrm{C}}$ & $10,62+1,1^{\mathrm{B}}$ & $10,95+0,0^{\mathrm{B}}$ \\
\hline \multirow[t]{2}{*}{ Cinzas } & $\mathrm{L}$ & $3,81+0,2^{\mathrm{A}}$ & $3,62+0,1^{A}$ & $3,75+0,0^{\mathrm{A}}$ & $2,5+0,1^{\mathrm{B}}$ & $2,67+0,4^{\mathrm{B}}$ & $2,82+0,3^{\mathrm{B}}$ \\
\hline & $\mathrm{P}$ & $4,10+0,3^{\text {B }}$ & $3,43+0,1^{\mathrm{C}}$ & $4,80+0,1^{\mathrm{A}}$ & $1,85+0,1^{\mathrm{E}}$ & $2,63+0,1^{\mathrm{D}}$ & $1,93+0,3^{\mathrm{E}}$ \\
\hline \multirow[t]{2}{*}{ Fibras } & $\mathrm{L}$ & $32,10+0,0^{A}$ & $18,60+0,1^{\mathrm{B}}$ & $14,40+0,0^{\mathrm{D}}$ & $6,80+0,0^{\mathrm{E}}$ & $6,20+0,0^{\mathrm{F}}$ & $15,10+0,0^{\mathrm{C}}$ \\
\hline & $\mathrm{P}$ & $27,85+0,1^{\mathrm{F}}$ & $35,85+0,1^{\mathrm{D}}$ & $30,26+0,0^{\mathrm{E}}$ & $40,94+0,0^{\mathrm{B}}$ & $41,69+0,1^{\mathrm{A}}$ & $40,17+0,0^{\mathrm{C}}$ \\
\hline \multirow[t]{2}{*}{ Carboidratos } & $\mathrm{L}$ & 20 & 27 & 45,2 & 53 & 60,1 & 38,2 \\
\hline & $\mathrm{P}$ & 34,32 & 24,99 & 23,9 & 31,53 & 25,8 & 26,6 \\
\hline
\end{tabular}

${ }^{\star}$ F1 : arroz cozido, feijão cozido, proteína texturizada de soja, óleo de soja, cenoura e couve-manteiga; F2: macarrão cozido, feijão cozido, proteína texturizada de soja, óleo de soja, cenoura e couve-manteiga; F3: arroz cozido, leite em pó, proteína texturizada de soja, óleo de soja, cenoura e couve-manteiga; F4: amido de milho cozido, ovo cozido, proteína texturizada de soja, óleo de soja, cenoura e couve-manteiga; F5: amido de milho cozido, sardinha, proteína texturizada de soja, óleo de soja, cenoura e couve-manteiga; F6: fubá cozido, ovo cozido, proteína texturizada de soja, óleo de soja, cenoura e couve-manteiga. ${ }^{1}$ Diferença entre os valores (desvio padrão). ${ }^{2}$ Valores assinalados com a mesma letra na mesma linha não diferem significativamente $(\mathrm{p}>0,05)$, segundo o teste de Tukey. $\mathrm{L}=$ Formulado líquido. $\mathrm{P}=$ Formulado em pó.

superiores para os dados da literatura em relação aos formulados desenvolvidos; no entanto, os formulados F1 e F2, tanto do líquido como do em pó, foram os que mais se aproximaram dos dados da literatura (UNIVERSIDADE DE SÃO PAULO, 2004).

Comparando os valores de lipídios da literatura com os teores apresentados pelos formulados, verificou-se que os formulados F1 e F2 dos formulados líquidos foram os que mais se aproximaram com os dados da literatura, ou seja, F1 (líquido) apresentou 18,95 g.100 g-1 e F2 (líquido) 19,97 g.100 g-1, já a literatura indica 20,7 g. $100 \mathrm{~g}^{-1}$ para F1 e 20,4 g. $100 \mathrm{~g}^{-1}$ para F2. Os outros formulados apresentaram valores inferiores aos da literatura (UNIVERSIDADE DE SÃO PAULO, 2004).

Os teores de fibras dos formulados em pó foram superiores aos valores apresentados pela Universidade de São Paulo (2004). Já os formulados líquidos foram os que mais ficaram concordantes com os dados da tabela de composição da Universidade de São Paulo (2004).

Os teores de cinzas ficaram muito próximos aos dados encontrados na literatura, com diferença nos formulados F4 e F6 dos formulados em pó, que apresentaram valores inferiores aos da literatura (UNIVERSIDADE DE SÃO PAULO, 2004).

As diferenças na composição centesimal do formulado em relação ao da Universidade de São Paulo (2004) se devem principalmente às variações na composição dos alimentos que fazem parte das formulações preparadas.

\subsection{Valor calórico}

$\mathrm{Na}$ Tabela 4, é apresentado o valor calórico total de cada formulado, tanto na forma líquida como em pó. Os formulados em pó apresentaram valores menores quando comparados com os dos líquidos da mesma composição. Os valores variaram de 131 a $216 \mathrm{Kcal}$. Dos formulados líquidos, o FL 4, foi considerado o de maior valor calórico e o FL 1 apresentou o menor. Para os formulados em pó, o de maior valor foi o FP 3 e o de menor foi o FP 4. A diferença pode ser justificada pela interferência da cocção dos alimentos e no modo de preparo. No caso dos formulados em pó ocorreu perda maior de nutrientes do que nos formulados líquidos.

A cocção é um processo que ocasiona trocas químicas, físico-químicas e estruturais dos componentes dos alimentos provocadas intencionalmente por efeito do calor. Nos diferentes métodos de cozimento, as formas de transferência de calor, a temperatura, a duração do processo, e o meio de cocção são alguns dos fatores responsáveis pelas alterações químicas e físicas que podem modificar o valor nutricional dos alimentos; além disso, períodos prolongados de cozimento causam mudanças estruturais em nível celular, provocando perda de nutrientes (GARCIA-ARIAS et al., 2003; POTTER; HOTCHKISS, 1995; WASSIMI; HOSFIELD; UEBERSAX, 1988).

No caso dos formulados em pó, o processo de cozimento foi prolongado, chegando a duas horas em forno convencional, isso pode ter influenciado significativamente na perda de nutrientes em comparação aos formulados líquidos.

Comparando os formulados em pó e líquido com os suplementos industrializados vendidos para idosos, os formulados apresentam valores calóricos mais baixos do que os industrializados, que em média apresentam $375 \mathrm{Kcal}$ em $250 \mathrm{~mL}$.

Estudos elaborados por Araújo e Menezes (2006), sobre elaboração de formulados líquidos com alimentos convencionais para alimentação via oral ou enteral, apresentaram em média $244 \mathrm{Kcal}$ em $250 \mathrm{~mL}$ do formulado, comparando-o com os formulados líquidos desenvolvidos neste estudo, que apresentaram em média $202 \mathrm{Kcal}$ por $250 \mathrm{~mL}$, o que se aproxima dos autores citados acima.

A distribuição do valor calórico total (VCT) em porcentagem pode ser observada na Tabela 5. Comparando os resultados dos formulados com os suplementos industrializados, os formulados que mais se aproximaram dos valores foram os formulados FL 4 e FP 4.

Os critérios de distribuição do valor calórico total para formulações via oral ou enteral são: carboidratos de 40 a 60\%, proteínas de 14 a $20 \%$ e lipídios de 30 a 35\%, caracterizando-se 
Tabela 4. Valor calórico (kcal) em $250 \mathrm{~mL} \cdot \mathrm{g}^{-1}$ de formulado em pó e líquido.

\begin{tabular}{|c|c|c|c|c|c|c|c|c|c|c|c|c|}
\hline \multirow[t]{3}{*}{ Nutrientes } & \multicolumn{12}{|c|}{ Formulados $^{1}$} \\
\hline & \multicolumn{2}{|c|}{ F 1} & \multicolumn{2}{|c|}{ F 2} & \multicolumn{2}{|c|}{$\mathrm{F} 3$} & \multicolumn{2}{|c|}{ F4 } & \multicolumn{2}{|c|}{ F5 } & \multicolumn{2}{|c|}{ F6 } \\
\hline & $\mathrm{L}^{2}$ & $\mathrm{P}^{3}$ & $\mathrm{~L}$ & $\mathrm{P}$ & $\mathrm{L}$ & $\mathrm{P}$ & $\mathrm{L}$ & $\mathrm{P}$ & $\mathrm{L}$ & $\mathrm{P}$ & $\mathrm{L}$ & $\mathrm{P}$ \\
\hline Carboidratos & 40 & 65 & 54 & 48 & 90 & 46 & 106 & 60 & 120 & 49 & 76 & 51 \\
\hline Proteína & 50 & 49 & 62 & 52 & 48 & 48 & 47 & 31 & 38 & 37 & 55 & 39 \\
\hline Lipídios & 85 & 35 & 90 & 37 & 58 & 69 & 63 & 40 & 55 & 46 & 74 & 47 \\
\hline Valor calórico total & 176 & 149 & 205 & 136 & 196 & 162 & 216 & 131 & 213 & 132 & 205 & 137 \\
\hline
\end{tabular}

${ }^{1} \mathrm{~F} 1$ : arroz cozido, feijão cozido, proteína texturizada de soja, óleo de soja, cenoura e couve-manteiga; F2: macarrão cozido, feijão cozido, proteína texturizada de soja, óleo de soja, cenoura e couve-manteiga; F3: arroz cozido, leite em pó, proteína texturizada de soja, óleo de soja, cenoura e couve-manteiga; F4: amido de milho cozido, ovo cozido, proteína texturizada de soja, óleo de soja, cenoura e couve-manteiga; F5: amido de milho cozido, sardinha, proteína texturizada de soja, óleo de soja, cenoura e couve-manteiga; T6: fubá cozido, ovo cozido, proteína texturizada de soja, óleo de soja, cenoura e couve-manteiga. ${ }^{2}$ Líquido (formulado líquido). ${ }^{3}$ Pó (formulado em pó).

como uma dieta padrão ou normoproteica, normoglicídica e normolipídica (BAXTER et al., 2000). Observando os resultados na Tabela 5, o formulado que se enquadrou nessas características foi o FL 5, podendo ser uma opção para indicação a pacientes domiciliares. Em relação aos outros formulados, grande parte apresentou as características hipoglicídica e hiperproteica.

Analisando os resultados de teores de lipídios dos formulados podemos classificá-los como hipolipídico (baixo teor de lipídios), normolipídico (teor normal) e hiperlipídico (alto teor de lipídios); essa classificação é baseada nas recomendações de lipídios para idosos maiores de 50 anos, segundo as DRI (DIETARY..., 2002), que é $20-35 \%$ do VET, considerando o valor energético diário total (VET) médio de $2100 \mathrm{Kcal}$.

As classificações dos formulados permitem o direcionamento de alguns para situações clínicas específicas, como ter restrições de gordura na alimentação.

Diversos fatores contribuem para o aumento da desnutrição dos idosos, e atender às necessidades de um idoso torna-se um desafio. Sabe-se que a mobilidade do indivíduo geralmente diminui com o avanço da idade, além da incidência elevada de intolerância à glicose. Muitas doenças catabólicas, estresse, podem aumentar as demandas energéticas, proteicas e lipídicas (FIGUEIREDO, 2005). Com isso, os formulados com características hiperproteicas podem auxiliar na ingestão diária de muitos idosos, principalmente àqueles com baixo poder aquisitivo e que têm alimentação desbalanceada.

$\mathrm{Na}$ Tabela 6 pode-se observar o percentual de adequação de macronutrientes dos formulados em $250 \mathrm{~mL}$ (1 porção). Essa adequação se baseou nas recomendações diárias de um idoso maior de 50 anos, estabelecidas pela DRI (DIETARY..., 2002), que seria para carboidratos, de 45 a $65 \%$; proteínas, de 10 a $35 \%$; e lipídios, de 20 a 35\% do VET, considerando o valor energético diário total (VET) médio de $2100 \mathrm{Kcal}$.

Analisando os resultados apresentados na Tabela 6, verificase que a média de adequação nos diferentes formulados, para os nutrientes, é para proteína 19\%, lipídios 9\% e carboidratos $5 \%$, em relação à ingestão diária recomendada para idosos maiores de 50 anos.

Observa-se que para a porcentagem do valor calórico total nos diferentes formulados encontra-se valor médio de 9,7\% para uma porção de $250 \mathrm{~mL}$ de formulado (Tabela 6). Considerando a ingestão diária de duas porções de formulado $(500 \mathrm{~mL})$, estima-se suprir aproximadamente $20 \%$ do valor calórico diário recomendado para idosos maior de 50 anos.

\subsection{Teores de ferro e diálise de ferro in vitro}

Os resultados para os teores de ferro e disponibilidade de ferro in vitro estão representados na Tabela 7.

Para os resultados de porcentagem de ferro disponível, representados na Tabela 7 , houve diferenças estatísticas nos diferentes formulados. Os formulados líquidos apresentaram porcentagens de ferro disponível mais elevadas quando comparados com as encontradas para os formulados em pó. Para os formulados líquidos, os percentuais variaram de 1,2 a $1,9 \%$ de ferro disponível e, no formulado em pó, de 0,04 a 0,12\%.

Os teores de ferro apresentados na Tabela 7 evidenciaram variações de acordo com as características e composições de cada formulado. Para os formulados líquidos, os teores variaram de 5,2 a 8,7 mg. $\mathrm{g}^{-1}$ e, nos formulados em pó, os teores variaram de 7,9 a $29,5 \mathrm{mg} \cdot \mathrm{g}^{-1}$, se diferenciando significativamente $(\mathrm{p}<0,05)$.

As principais fontes de ferro nos formulados estudados foram: feijão, ovo, sardinha, proteína texturizada de soja e couve. As formulações apresentaram entre 10 e $15 \mathrm{~g}$ de proteína texturizada de soja em sua composição, representando uma proporção de 8 a 12\% da composição dos formulados.

O teor de ferro encontrado na literatura para proteína texturizada de soja é de $7 \mathrm{mg} .100 \mathrm{~g}^{-1}$ segundo a Universidade de Campinas (2006). Considerando que os formulados desenvolvidos apresentem em sua composição teores entre 10 e $15 \mathrm{~g}$ de proteína texturizada de soja, estima-se que tenha de 0,7 a $1 \mathrm{mg} \cdot 100 \mathrm{~g}^{-1}$ de ferro, de acordo com a literatura citada.

Considerando que a proteína texturizada de soja represente de 8 a 12\% da composição dos formulados, essa porcentagem representa teores concordantes ao estimado pela literatura (UNIVERSIDADE DE CAMPINAS, 2006). Ao analisar todos os ingredientes da composição dos formulados e estimar os teores de ferro para cada formulado de acordo com a literatura (UNIVERSIDADE DE CAMPINAS, 2006), verifica-se que os teores foram superiores aos teores estimados pela literatura.

Levando em consideração os teores de ferro, apresentados nos diferentes formulados (Tabela 7), confirmou-se que o teor de ferro não é importante, mas sim, a sua disponibilidade no organismo, de acordo com Machado, Canniatti-Brazaca e 
Tabela 5. Distribuição do percentual de valor calórico total (\%) das formulações.

\begin{tabular}{|c|c|c|c|c|c|c|c|c|c|c|c|c|c|}
\hline \multirow[t]{3}{*}{ Nutrientes } & \multicolumn{12}{|c|}{ Diferentes formulados ${ }^{2}$} & \multirow[t]{3}{*}{$\operatorname{Ref}^{4}$} \\
\hline & \multicolumn{2}{|c|}{$\mathrm{F} 1^{1}$} & \multicolumn{2}{|c|}{$\mathrm{F} 2$} & \multicolumn{2}{|c|}{ F3 } & \multicolumn{2}{|c|}{$\mathrm{F} 4$} & \multicolumn{2}{|c|}{ F5 } & \multicolumn{2}{|c|}{ F6 } & \\
\hline & $\mathrm{L}^{2}$ & P3 & $\mathrm{L}$ & $\mathrm{P}$ & $\mathrm{L}$ & $\mathrm{P}$ & $\mathrm{L}$ & $\mathrm{P}$ & $\mathrm{L}$ & $\mathrm{P}$ & $\mathrm{L}$ & $\mathrm{P}$ & \\
\hline Carboidratos & 23 & 44 & 26 & 35 & 46 & 28 & 49 & 46 & 57 & 37 & 37 & 37 & $50 \%$ \\
\hline Proteína & 29 & 33 & 30 & 38 & 24 & 30 & 22 & 24 & 18 & 28 & 27 & 28 & $16 \%$ \\
\hline Lipídios & 49 & 24 & 44 & 27 & 29 & 42 & 29 & 30 & 26 & 35 & 36 & 34 & $34 \%$ \\
\hline
\end{tabular}

${ }^{1}$ F1: arroz cozido, feijão cozido, proteína texturizada de soja, óleo de soja, cenoura e couve-manteiga; F2: macarrão cozido, feijão cozido, proteína texturizada de soja, óleo de soja, cenoura e couve-manteiga; F3: arroz cozido, leite em pó; proteína texturizada de soja, óleo de soja, cenoura e couve-manteiga; F4: amido de milho cozido, ovo cozido, proteína texturizada de soja, óleo de soja, cenoura e couve-manteiga; F5: amido de milho cozido, sardinha, proteína texturizada de soja, óleo de soja, cenoura e couve-manteiga; F6: fubá cozido, ovo cozido, proteína texturizada de soja, óleo de soja, cenoura e couve-manteiga. ${ }^{2} \mathrm{~L}$ (formulado líquido). ${ }^{3} \mathrm{P}$ (formulado em pó). ${ }^{4}$ Referência: suplementos industrializados para idosos.

Tabela 6. Percentual (\%) de adequação de macronutrientes dos formulados em $250 \mathrm{~mL}$ (1 porção) em relação à ingestão diária recomendada para idosos.

\begin{tabular}{|c|c|c|c|c|c|c|c|c|c|c|c|c|}
\hline \multirow[t]{3}{*}{ Nutrientes } & \multicolumn{12}{|c|}{ Formulados $^{1}$} \\
\hline & \multicolumn{2}{|c|}{$\mathrm{F} 1$} & \multicolumn{2}{|c|}{ F2 } & \multicolumn{2}{|c|}{ F3 } & \multicolumn{2}{|c|}{ F4 } & \multicolumn{2}{|c|}{ F5 } & \multicolumn{2}{|c|}{ F6 } \\
\hline & $\mathrm{L}^{2}$ & $\mathrm{P}$ & $\mathrm{L}$ & $\mathrm{P}$ & $\mathrm{L}$ & $\mathrm{P}$ & $\mathrm{L}$ & $\mathrm{P}$ & $\mathrm{L}$ & $\mathrm{P}$ & $\mathrm{L}$ & $\mathrm{P}$ \\
\hline Carboidratos \% & 3,2 & 5,2 & 4,3 & 3,8 & 7,2 & 3,6 & 8,4 & 4,8 & 9,5 & 3,91 & 6,1 & 4,0 \\
\hline Proteína \% & 19,9 & 19,3 & 24,4 & 20,5 & 18,9 & 19,0 & 19,0 & 12,0 & 14,9 & 14,5 & 22,0 & 15,0 \\
\hline Lipídios \% & 13,5 & 5,6 & 14,3 & 5,9 & 9,2 & 10,9 & 10,0 & 6,3 & 8,7 & 7,2 & 12,0 & 7,5 \\
\hline Valor calórico \% & 8,4 & 7,1 & 9,8 & 6,5 & 9,3 & 7,7 & 10,0 & 6,2 & 10,1 & 6,3 & 9,8 & 6,5 \\
\hline
\end{tabular}

${ }^{1} \mathrm{~F} 1$ : arroz cozido, feijão cozido, proteína texturizada de soja, óleo de soja, cenoura e couve-manteiga; F2: macarrão cozido, feijão cozido, proteína texturizada de soja, óleo de soja, cenoura e couve-manteiga; F3: arroz cozido, leite em pó, proteína texturizada de soja, óleo de soja, cenoura e couve-manteiga. F4: amido de milho cozido, ovo cozido, proteína texturizada de soja, óleo de soja, cenoura e couve-manteiga. F5: amido de milho cozido, sardinha, proteína texturizada de soja, óleo de soja, cenoura e couve-manteiga; F6: fubá cozido, ovo cozido, proteína texturizada de soja, óleo de soja, cenoura e couve-manteiga. ${ }^{2} \mathrm{~L}$ (formulado líquido) e $\mathrm{P}$ (formulado em pó).

Piedade (2006). Podendo ser influenciado por diversos fatores, entre os inibidores da absorção do ferro, estão alguns dos componentes das fibras (hemicelulose e lignina), o ácido oxálico, o ácido fítico e outros polifenóis (YAMADA et al., 2003). Esses inibidores podem estar relacionados aos resultados apresentados na Tabela 7, ou seja, mesmo apresentando altos teores de ferro, no caso os FP4 e FP5, apresentaram baixas quantidades de ferro disponível.

Verifica-se que as composições dos formulados, principalmente as formulações FP4 e FP5, influenciaram nos resultados da porcentagem de ferro disponível, nestes casos, pelas maiores quantidades de proteína texturizada de soja do que os outros formulados observados.

Segundo Yamada et al. (2003), a soja e os seus derivados apresentam elevadas quantidades de ferro ( 9 a $\left.13 \mathrm{mg} \cdot \mathrm{g}^{-1}\right)$. Entretanto, apesar de aparentemente serem boas fontes de ferro, sua disponibilidade biológica é baixa. Isso se dá pela sua forma química e pela presença de itens alimentares que promovem ou inibem a sua absorção.

Um desses inibidores da soja pode estar relacionado com os componentes das fibras (hemicelulose e lignina). Observando os teores de fibras nos diferentes formulados (Tabela 3 ), verifica-se que os formulados $\mathrm{F} 4 \mathrm{e} \mathrm{F} 5 \mathrm{em}$ pó apresentaram teores superiores de fibras em relação aos outros, o que pode ter influenciado nos resultados de porcentagem de ferro dialisável nesses formulados.

Os formulados líquidos apresentaram características diferentes, comparados aos formulados em pó em quantidades de ferro dialisável, apesar de apresentarem os mesmos alimentos em sua composição. Os formulados líquidos apresentaram quantidade de ferro dialisável maior do que os formulados em pó, provavelmente devido ao processamento realizado.

Este fato pode ser justificado pelo processamento realizado nos formulados em pó, em que houve aquecimento em forno convencional, promovendo a secagem para a posterior reconstituição, influenciando de forma negativa a disponibilidade de ferro nos formulados em pó.

Em estudo sobre os métodos de cocção e sua relação com o tempo de cozimento de vegetais fontes de ferro, verificou-se que a cocção provoca perdas de minerais e que o tempo de cozimento foi determinante nessas perdas, ou seja, quanto maior o tempo maior a perda (KAWASHIMA; VALENTE SOARES, 2005). Em estudo com macarrão enriquecido com ferro, verificou-se que, em processo de cozimento, o macarrão fica com $72 \%$ de ferro e que há perda no processo de cozimento (CARVALHO; SILVA; PARRA, 1997).

\subsection{Digestibilidade de proteína}

Os valores de digestibilidade da proteína estão apresentados na Tabela 8.

Os valores de digestibilidade para os formulados em pó variaram de 68,20 a 75,71\% e os formulados líquidos variaram de 61,77 a $81,22 \%$ e mostraram diferenças estatísticas significantes $(\mathrm{p}<0,05)$. Esses valores indicam que a digestibilidade dos formulados compara-se às proteínas de origem vegetal, pois são as principais fontes proteicas dos formulados (SGARBIERI, 1996). 
Tabela 7. Teores de ferro (mg.g $\left.\mathrm{g}^{-1}\right)$ e ferro disponível (\%).

\begin{tabular}{clrrr}
\hline Formulados $^{1}$ & \multicolumn{2}{c}{ Teor de ferro $\left(\mathrm{mg} \cdot \mathrm{g}^{-1}\right)$} & \multicolumn{2}{c}{ Ferro disponível (\%) } \\
\cline { 2 - 5 } & Líquido & Pó & \multicolumn{2}{c}{ Líquido } \\
\hline F1 & $5,2+0,2^{2 \mathrm{cc}}$ & $11,6+1,6^{\mathrm{c}}$ & $1,8+0,0^{\mathrm{b}}$ & $0,09+0,0^{\mathrm{a}}$ \\
F2 & $6,8+0,8^{\mathrm{b}}$ & $10,3+0,8^{\mathrm{d}}$ & $1,2+0,0^{\mathrm{d}}$ & $0,1+0,0^{\mathrm{a}}$ \\
F3 & $4,5+1,2^{\mathrm{d}}$ & $8,2+1,4^{\mathrm{e}}$ & $1,9+0,0^{\mathrm{a}}$ & $0,11+0,0^{\mathrm{a}}$ \\
F4 & $4,6+0,9^{\mathrm{d}}$ & $29,5+1,1^{\mathrm{a}}$ & $1,7+0,0^{\mathrm{c}}$ & $0,04+0,0^{\mathrm{b}}$ \\
F5 & $4,1+0,5^{\text {ed }}$ & $23,1+1,1^{\mathrm{b}}$ & $1,8+0,2^{\mathrm{b}}$ & $0,04+0,0^{\mathrm{b}}$ \\
F6 & $8,7+0,8^{\mathrm{a}}$ & $7,9+0,2^{\mathrm{f}}$ & $0,8+0,0^{\mathrm{e}}$ & $0,12+0,0^{\mathrm{a}}$ \\
\hline
\end{tabular}

${ }^{1} \mathrm{~F} 1$ : arroz cozido, feijão cozido, proteína texturizada de soja, óleo de soja, cenoura e couve-manteiga. F2: macarrão cozido, feijão cozido, proteína texturizada de soja, óleo de soja, cenoura e couve-manteiga. F3: arroz cozido, leite em pó, proteína texturizada de soja, óleo de soja, cenoura e couve-manteiga. F4: amido de milho cozido, ovo cozido, proteína texturizada de soja, óleo de soja, cenoura e couve-manteiga. F5: amido de milho cozido, sardinha, proteína texturizada de soja, óleo de soja, cenoura e couve-manteiga. F6: fubá cozido, ovo cozido, proteína texturizada de soja, óleo de soja, cenoura e couve-manteiga. ${ }^{2}$ Média + desvio padrão. ${ }^{3}$ Letras diferentes na vertical indicam diferença estatística entre as médias ( $\mathrm{p}<0,05$ ).

Tabela 8. Digestibilidade da proteína (\%) dos formulados em pó e líquido.

\begin{tabular}{ccc}
\hline Diferentes Formulados $^{3}$ & Formulado em pó $^{\text {Formulado líquido }}$ \\
\hline F1 & $73,04+1,1^{1 \mathrm{~B} 2}$ & $61,77+0,16^{\mathrm{F}}$ \\
F2 & $68,20+1,9^{\mathrm{F}}$ & $75,17+0,96^{\mathrm{D}}$ \\
F3 & $75,71+0,8^{\mathrm{A}}$ & $79,08+1,56^{\mathrm{B}}$ \\
F4 & $70,29+1,1^{\mathrm{C}}$ & $78,51+0,88^{\mathrm{C}}$ \\
F5 & $69,54+1,1^{\mathrm{D}}$ & $67,26+0,64^{\mathrm{E}}$ \\
F6 & $68,99+1,1^{\mathrm{E}}$ & $81,22+0,44^{\mathrm{A}}$ \\
\hline
\end{tabular}

${ }^{1}$ Média + desvio padrão. ${ }^{2}$ Letras diferentes na vertical indicam diferença estatística entre as médias $(\mathrm{p}<0,05) \cdot{ }^{3} \mathrm{~F} 1$ : arroz cozido, feijão cozido, proteína texturizada de soja, óleo de soja, cenoura e couve-manteiga. F2: macarrão cozido, feijão cozido, proteína texturizada de soja, óleo de soja, cenoura e couve-manteiga. F3: arroz cozido, leite em pó, proteína texturizada de soja, óleo de soja, cenoura e couve-manteiga. F4: amido de milho cozido, ovo cozido, proteína texturizada de soja, óleo de soja, cenoura e couve-manteiga. F5: amido de milho cozido, sardinha, proteína texturizada de soja, óleo de soja, cenoura e couve-manteiga. F6: fubá cozido, ovo cozido, proteína texturizada de soja, óleo de soja, cenoura e couve-manteiga.

A digestibilidade representa a qualidade proteica da dieta e pode ser influenciada por vários compostos inibidores de enzimas digestivas, hemaglutininas e polifenóis, entre outros. Quando certas ligações peptídicas não são hidrolisadas no processo digestivo, parte da proteína é excretada nas fezes ou transformada em produtos do metabolismo pelos micro-organismos do intestino grosso (SGARBIERI, 1996). De acordo com o mesmo autor, as proteínas de origem animal apresentam digestibilidade superior a $95 \%$ e as de origem vegetal, abaixo de $80 \%$.

Araújo e Menezes (2005) elaboraram formulados para nutrição oral e enteral contendo carne bovina, ovo, chicória, cenoura, fubá de milho, extrato hidrossolúvel de soja, óleo de soja e obtiveram digestibilidade de $92 \%$, muito próximo à digestibilidade de alimentos de origem animal. Os teores encontrados por Araújo e Menezes (2005) foram superiores aos encontrados (Tabela 8), pois, apenas uma formulação, F6, continha em sua composição proteína de origem animal, o ovo. Já as outras formulações apresentaram valores compatíveis com literatura em alimentos de origem proteica vegetal, ou seja, abaixo de $80 \%$.

Segundo Pires et al. (2006), ao lado das fontes de proteína animal, classicamente consideradas como de alto valor biológico, tem sido demonstrado que misturas de vegetais, como de um cereal e de uma leguminosa, também resultam em misturas proteicas de alto valor biológico.

No Brasil, a principal fonte proteica da alimentação é derivada da ingestão de arroz e feijão. Infelizmente esse hábito saudável vem diminuindo na alimentação do brasileiro (INSTITUTO BRASILEIRO DE GEOGRAFIA E ESTATÍSTICA, 2004). A mistura arroz e feijão tem adequado teor nitrogenado, supre os aminoácidos essenciais e tem digestibilidade ao redor de $80 \%$. A formulação F1 em pó, que apresenta em sua composição arroz e feijão, apresentaram digestibilidade de $73 \%$, valor inferior a de $80 \%$ (PIRES et al., 2006). Toledo e Canniatti-Brazaca (2008) avaliaram a digestibilidade das proteínas do feijão carioca submetido à cocção em panela aberta, panela de pressão e micro-ondas, com e sem maceração e cozido ou não na água de maceração, encontrando valores que variaram de 69,33\%, para o feijão cozido em panela de pressão sem aproveitamento da água de maceração, a 82,59\% para o feijão cozido em panela aberta sem ser realizada a maceração.

Pires et al. (2006) avaliaram a qualidade proteica de diferentes fontes de alimentos vegetais e verificaram uma variação de $89,44 \%$ a $71,76 \%$ na digestibilidade, reportando $89,44 \%$ para farinha de trigo, $86,41 \%$ para proteína texturizada de soja (PTS), $82 \%$ fubá, 78,7\% feijão cozido e $71,76 \%$ farinha de soja.

A análise dos grãos de soja cru e cozido realizada por Toledo et al. (2007) comprovou que a digestibilidade dos grãos cozidos é devida ao alto teor de inibidor de tripsina em grãos crus, o qual pode interferir na hidrólise das proteínas em sua solubilização.

Para Sgarbieri (1996), a desnaturação da proteína no processo melhora a digestibilidade por facilitar a ação proteolítica das enzimas digestivas. Para Nunes e Baptista (2001), o processo térmico excessivo pode causar decréscimo na digestibilidade da proteína devido à formação de ligações cruzadas. Essa constatação pode justificar o baixo teor de digestibilidade em alguns formulados em pó em comparação com alguns formulados líquidos (Tabela 8).

Ferreira, Fialho e Teixeira (1997) citaram que a fibra presente nos alimentos exerce efeito negativo na digestão da proteína graças a sua associação com a lignocelulose, reduzindo o seu aproveitamento. 
Quando analisados os teores de fibras (Tabela 3), observamos que os altos valores apresentados nas formulações puderam justificar também a baixa digestibilidade, principalmente, nos formulados em pó. Foi observado que o F1 líquido apresentou maior teor de fibra do que o F1 em pó o que pode ter influenciado em sua digestibilidade, uma vez que esta foi mais baixa do que a do formulado em pó.

\subsection{Fatores antinutricionais}

A biodisponibilidade de um nutriente relaciona-se com a capacidade do organismo em utilizá-lo após sua ingestão. Os alimentos possuem em sua composição certos componentes químicos capazes de causar diminuição da utilização orgânica de alguns nutrientes, sendo tais compostos denominados fatores antinutricionais. Os fatores antinutricionais como os fenólicos, ácido fítico, entre outros, quando ingeridos em altas quantidades e de forma crônica podem ser responsáveis pelo desenvolvimento de quadros de carências nutricionais, devido à não utilização orgânica dos nutrientes ofertados pelos alimentos (SOUZA et al., 2005).

$\mathrm{O}$ ácido fítico, ou mioinositol hexafosfato $\left(\mathrm{C}_{6} \mathrm{H}_{18} \mathrm{O}_{24} \mathrm{P}_{6}\right)$, é um componente natural da semente, constituindo de 1 a $3 \%$ do peso nas leguminosas e cereais, o que responde por $60 \%$ a 90\% do fósforo total (CÚNEO; FARFAN; CARRARO, 2000).

Os compostos fenólicos estão amplamente distribuídos no reino vegetal e são originados do metabolismo secundário das plantas, essenciais para o seu crescimento e reprodução. Além disso, são definidos como substâncias que possuem um anel aromático com um ou mais substituintes hidroxílicos, incluindo seus grupos funcionais (MALACRIDA; MOTTA, 2005).

Os compostos fenólicos possuem estrutura variável e, com isso, são multifuncionais. Existem cerca de cinco mil fenóis, dentre eles, destacam-se os flavonoides, ácidos fenólicos, fenóis simples, cumarinas, taninos, ligninas e tocoferóis (ANGELO; JORGE, 2007).

A Tabela 9 apresenta os teores de fenólicos totais e ácido fítico dos formulados.

Para os resultados de ácido fítico, os formulados líquidos apresentaram maiores valores se comparados com os formulados em pó. As formulações líquidas tiveram diferenças estatísticas significativas $(\mathrm{p}<0,05)$. O formulado F2 (líquido) foi o que apresentou o maior valor (7,55 $\left.\mathrm{mg} \cdot \mathrm{g}^{-1}\right)$, e o F5 (líquido), o menor valor $\left(3,31 \mathrm{mg} \cdot \mathrm{g}^{-1}\right)$. Analisando os resultados dos formulados em pó, verifica-se que o formulado que apresentou o maior valor foi o F1 (4,26 mg. $\left.\mathrm{g}^{-1}\right)$, e o menor valor, foi o F5 (1,34 mg. $\left.\mathrm{g}^{-1}\right)$.

Segundo a literatura, alimentos como feijão apresentam quantidades consideráveis de ácido fítico. A quantidade encontrada por Martini (2002) foi de 10,66 mg.100 g $\mathrm{g}^{-1}$. Moura e Canniatti-Brazaca (2006) encontraram 8,83 mg.100 g $\mathrm{g}^{-1}$, enquanto Guzmán-Maldonado, Acosta-Gallego e Paredes-López $(2000)$ verificaram para o feijão cozido a variação de 10 a $18,3 \mathrm{mg} .100 \mathrm{~g}^{-1}$ para espécies de feijões selvagens, de 7,3 a $10,8 \mathrm{mg} \cdot 100 \mathrm{~g}^{-1}$ para os feijões comuns.

Os valores encontrados (Tabela 9) confirmaram os resultados para ácido fítico citados por outros autores (MARTINI, 2002; MOURA; CANNIATTI-BRAZACA, 2006; GUZMÁN-MALDONADO; ACOSTA-GALLEGO; PAREDESLÓPEZ, 2000). F1 e F2 apresentaram os maiores valores de ácido fítico, tanto para o formulado líquido como para o em pó. Na composição desses formulados, que apresentam 30,5\% do ingrediente feijão cozido, quando comparados estes com dados da literatura, essa porcentagem representa $3,25 \mathrm{mg} \cdot \mathrm{g}^{-1}$ (MARTINI, 2002) e 2,7 mg.g-1 (MOURA; CANNIATTIBRAZACA, 2006) de ácido fítico, justificando os altos teores de elemento nos formulados F1 e F2.

A proteína texturizada de soja está presente em todos os formulados, variando numa proporção de 8 a $12 \%$ da quantidade total e contém ácido fítico por ser uma fonte vegetal. Estudos apontam que a soja contém $20,36 \mathrm{mg} .100 \mathrm{~g}^{-1}$ de ácido fítico (MARTINEZ et al., 2007), e seus derivados têm de 12 a $16 \mathrm{mg} .100 \mathrm{~g}^{-1}$ de ácido fítico (RIBEIRO; IDA; OLIVEIRA, 1999). Comparado com dados da literatura, o valor médio de ácido fitico encontrado em derivados de soja foi de aproximadamente, $14 \mathrm{mg} .100 \mathrm{~g}^{-1}$. Os formulados com proteína texturizada de soja variaram entre 10 e $15 \mathrm{~g}$, apresentando teores entre $1,98 \mathrm{e}$ $3,2 \mathrm{mg} . \mathrm{g}^{-1}$ de ácido fítico, e quando adicionados os valores de ácido fítico presente no feijão, mais o da proteína texturizada de soja, foram observados altos valores (Tabela 9), principalmente nas formulações F1 e F2, tanto do líquido como do em pó.

Os teores de fenólicos totais (Tabela 9) apresentaram, ao contrário dos teores de ácido fítico, valores mais altos para os formulados em pó do que para os formulados líquidos. Entre os formulados em pó, o formulado F6 apresentou o maior valor,

Tabela 9. Teor de fenólicos totais (mg.g $\left.\mathrm{g}^{-1}\right)$ e ácido fítico (mg.g $\left.\mathrm{g}^{-1}\right)$ nos diferentes formulados.

\begin{tabular}{|c|c|c|c|c|}
\hline \multirow[t]{2}{*}{ Formulados ${ }^{3}$} & \multicolumn{2}{|c|}{ Ácido fítico (mg.g $\left.{ }^{-1}\right)$} & \multicolumn{2}{|c|}{ Fenólicos totais $\left(\mathrm{mg} \cdot \mathrm{g}^{-1}\right)$} \\
\hline & Líquido & Pó & Líquido & Pó \\
\hline F1 & $5,65+1,0^{1 \mathrm{~B} 2}$ & $4,26+0,3^{A}$ & $6,72+0,1^{\mathrm{F}}$ & $10,66+0,2^{\mathrm{E}}$ \\
\hline $\mathrm{F} 2$ & $7,55+1,0^{\mathrm{A}}$ & $3,15+0,1^{\mathrm{B}}$ & $6,95+0,2^{\mathrm{E}}$ & $10,03+0,4^{\mathrm{F}}$ \\
\hline F3 & $5,46+0,4^{\mathrm{C}}$ & $3,08+0,8^{\mathrm{C}}$ & $7,75+0,2^{A}$ & $14,93+0,2^{\mathrm{D}}$ \\
\hline $\mathrm{F} 4$ & $5,07+0,2^{\mathrm{D}}$ & $2,04+0,1^{\mathrm{D}}$ & $7,09+0,3^{\mathrm{D}}$ & $23,24+0,1^{\mathrm{B}}$ \\
\hline F5 & $3,31+0,1^{\mathrm{F}}$ & $1,34+0,8^{\mathrm{F}}$ & $7,18+0,2^{\mathrm{B}}$ & $16,57+0,3^{C}$ \\
\hline F6 & $3,77+0,3^{\mathrm{E}}$ & $1,91+0,8^{\mathrm{E}}$ & $7,14+0,2^{\mathrm{C}}$ & $25,63+0,4^{\mathrm{A}}$ \\
\hline
\end{tabular}

${ }^{1}$ Média + desvio padrão. ${ }^{2}$ Letras diferentes na vertical indicam diferença estatística entre as médias $(\mathrm{p}<0,05)$. ${ }^{3} \mathrm{~F} 1$ : arroz cozido, feijão cozido, proteína texturizada de soja, óleo de soja, cenoura e couve-manteiga; F2: macarrão cozido, feijão cozido, proteína texturizada de soja, óleo de soja, cenoura e couve-manteiga. F3: arroz cozido, leite em pó, proteína texturizada de soja, óleo de soja, cenoura e couve-manteiga; F4: amido de milho cozido, ovo cozido, proteína texturizada de soja, óleo de soja, cenoura e couve-manteiga. F5: amido de milho cozido, sardinha, proteína texturizada de soja, óleo de soja, cenoura e couve-manteiga. F6: fubá cozido, ovo cozido, proteína texturizada de soja, óleo de soja, cenoura e couve-manteiga. 
25,63 mg.g ${ }^{-1}$ e o F2 o menor, com 10,03 mg.g-1 observando-se que, entre as formulações estudadas, os valores mostraram diferenças estatísticas $(\mathrm{p}<0,05)$. E entre os formulados líquidos, o F5 apresentou o maior teor, 7,18 mg.g ${ }^{-1}$, e F1 o menor, com $6,72 \mathrm{mg} \cdot \mathrm{g}^{-1}$, e esta diferença é estatisticamente significante $(\mathrm{p}<0,05)$.

$\mathrm{O}$ aquecimento exerceu influência nas quantidades de compostos fenólicos totais pós-cocção. No caso de cozimento em água, verificou-se a diminuição da quantidade dos fenóis, pois parte destes são solúveis em água. Os formulados elaborados nesta pesquisa mostraram-se sujeitos ao processo de aquecimento ao forno a $180{ }^{\circ} \mathrm{C}$, processo de desidratação para transformação do produto em pó, o que pode ter alterado a quantidade dessas substâncias.

Segundo Sgarbieri (1996), os compostos fenólicos podem reagir com outros nutrientes, tais como proteína. Alguns compostos não hidrolisados estão presentes na fração de fibra alimentar em diferentes alimentos e considerados indigeríveis, principalmente as leguminosas e cereais (SILVA; SILVA, 1999). Para justificar esse aumento de fenólicos totais nos formulados em pó, pode-se considerar que no processo de desidratação em forno ocorreram ligações que podem ter influenciado no aumento dos teores, principalmente nos formulados com teores elevados de fibras, no caso, o F4 e F6.

\section{$3.6 \beta$-caroteno}

A Tabela 10 mostra o teor em $\mu \mathrm{g} .100 \mathrm{~g}^{-1}$ de $\beta$-caroteno nos formulados e o valor de vitamina A total em $\mu \mathrm{g} .100 \mathrm{~g}^{-1} \mathrm{de}$ Atividade de Retinol Equivalente (RAE) e $\mu \mathrm{g} .100 \mathrm{~g}^{-1}$ de Retinol Equivalente (RE) em base seca.

A principal fonte de vitamina A foi proveniente de vegetais, que possuem substâncias pró-vitamina do grupo de substâncias denominadas carotenoides, como o $\beta$-Caroteno. Para determinação de vitamina A nos formulados realizou-se o cálculo da equivalência de vitamina A a partir do teor de $\beta$-caroteno presente nos formulados, considerando base seca.

Campos e Rosado (2005) analisaram as novas tendências para a realização dos cálculos para fatores de conversão propostos pelo Institute of Medicine (IOM), o qual sugere o uso de RAE (atividade de retinol equivalente) ao invés da denominação RE. Cada Equivalente de Atividade de Retinol corresponde a $1 \mathrm{~g}$ de retinol, ou a $12 \mu \mathrm{g}$ de $\beta$-caroteno ou $24 \mu \mathrm{g}$ de outros carotenoides, que têm atividade de vitamina $A$.

Os valores de $\beta$-caroteno dos formulados líquido e em pó variaram de acordo com as composições de cada formulado, diferenciando-se estatisticamente. Os formulados em líquidos apresentaram teores mais elevados do que os formulados em pó, com exceção de F4 e F6. A maior parte dos formulados em pó apresentaram menor valor, provavelmente devido ao aquecimento e manipulação maior do formulado em pó do que do líquido.

Pinheiro-Santana et al. (1998) analisaram $\beta$-caroteno e carotenoides totais em cenoura em diferentes procedimentos domésticos e encontraram em base úmida, $72,75 \mu \mathrm{g} .100 \mathrm{~g}^{-1}$ na cenoura cozida sem pressão, e $1008,74 \mu \mathrm{g} .100 \mathrm{~g}^{-1}$ na cenoura desidratada em forno convencional. Na base seca, a cenoura cozida sem pressão e cenoura desidratada apresentaram 909,53 e $1062,87 \mu \mathrm{g} .100 \mathrm{~g}^{-1}$ de $\beta$-caroteno, respectivamente. Nos alimentos desidratados, os valores foram maiores do que no alimento sem desidratação. No caso dos formulados em estudo, eles foram elaborados em desidratação em forno convencional e reconstituído o que pode ter influenciado nos resultados (Tabela 10).

Cerca de 10 a $50 \%$ do total de $\beta$-caroteno consumido é absorvido pelo trato gastrointestinal, e, dentro da parede do intestino, é parcialmente convertido à vitamina A (GARCIACASAL et al., 1998). Em países em desenvolvimento de $70 \%$ a $90 \%$ da vitamina A é proveniente dos carotenoides presentes nas frutas e vegetais (MACHADO; CANNIATTI-BRAZACA; PIEDADE, 2006).

Neste sentido, as principais fontes de $\beta$-caroteno nos formulados estudados são provenientes de cenoura, couve, ovos e outros como sardinha e leite em pó.

Machado, Canniatti-Brazaca e Piedade (2006) encontraram $6605,5 \mu \mathrm{g} .100 \mathrm{~g}^{-1}$ de $\beta$-caroteno na cenoura cozida. Nos formulados, a quantidade de cenoura cozida representa de 15 a $17 \%$ de sua composição, ou seja, em porcentagem corresponderia aos resultados apresentados na Tabela 10 para

Tabela 10. $\beta$-caroteno ( $\left.\mu \mathrm{g} .100 \mathrm{~g}^{-1}\right)$ e Atividade de Retinol Equivalente (RAE) ( $\left.\mu \mathrm{g} \cdot 100 \mathrm{~g}^{-1}\right)$ nos formulados em base seca.

\begin{tabular}{|c|c|c|c|c|c|c|}
\hline \multirow[t]{3}{*}{ Formulados $^{3}$} & \multicolumn{2}{|c|}{$\beta$-caroteno $\left(\mu \mathrm{g} .100 \mathrm{~g}^{-1}\right)$} & \multicolumn{2}{|c|}{$\mathrm{RE}^{4}\left(\mu \mathrm{g} .100 \mathrm{~g}^{-1}\right)$} & \multicolumn{2}{|c|}{$\operatorname{RAE}^{5}\left(\mu \mathrm{g} .100 \mathrm{~g}^{-1}\right)$} \\
\hline & \multicolumn{2}{|c|}{ Formulados } & \multicolumn{2}{|c|}{ Formulados } & \multicolumn{2}{|c|}{ Formulados } \\
\hline & Pó & Líquido & Pó & Líquido & Pó & Líquido \\
\hline F1 & $11112+9,5^{1 \mathrm{c} 2}$ & $18807+30,6^{\mathrm{b}}$ & 463 & 783 & 926 & 1567 \\
\hline F2 & $15438+6,4^{b}$ & $18609+54,9^{c}$ & 643 & 775 & 1286 & 1550 \\
\hline F3 & $10537+22,2^{e}$ & $17398+16,6^{\mathrm{d}}$ & 439 & 724 & 878 & 1449 \\
\hline F4 & $26159+84,7^{a}$ & $16176+6,4^{\mathrm{e}}$ & 1089 & 674 & 2179 & 1348 \\
\hline
\end{tabular}

${ }^{1}$ Média + desvio padrão. ${ }^{2}$ Letras diferentes na vertical indicam diferença estatística entre as médias ( $\left.<<0,05\right)$. ${ }^{3} \mathrm{~F} 1$ : arroz cozido, feijão cozido, proteína texturizada de soja, óleo de soja, cenoura e couve-manteiga. F2: macarrão cozido, feijão cozido, proteína texturizada de soja, óleo de soja, cenoura e couve-manteiga. F3: arroz cozido, leite em pó, proteína texturizada de soja, óleo de soja, cenoura e couve-manteiga; F4: amido de milho cozido, ovo cozido, proteína texturizada de soja, óleo de soja, cenoura e couve-manteiga. F5: amido de milho cozido, sardinha, proteína texturizada de soja, óleo de soja, cenoura e couve-manteiga. F6: fubá cozido, ovo cozido, proteína texturizada de soja, óleo de soja, cenoura e couve-manteiga. ${ }^{4} \mathrm{RE}$ (etinol equivalente). ${ }^{5} \mathrm{RAE}$ (Atividade de retinol equivalente). 
os formulados líquidos de 1171,1 a $4420 \mu \mathrm{g}^{-g^{-1}}$ de $\beta$-caroteno, e entre 1244 a $3923 \mu \mathrm{g} . \mathrm{g}^{-1}$ de $\beta$-caroteno nos formulados em pó. Sendo, portanto, valores inferiores.

Nos formulados, foram adicionados $24 \mathrm{~g}$ de cenoura cozida, o que corresponde de 14,2 a 16,9\% do peso total de ingredientes dos formulados. Considerando essa porcentagem nos resultados apresentados na Tabela 10, os valores de atividade de retinol equivalente (RAE) provenientes da cenoura, nos formulados líquidos, variaram de 650 a $2456 \mu \mathrm{g}$ (RAE) e, nos formulados em pó, de 691 a $2179 \mu \mathrm{g}$ (RAE). Cada $100 \mathrm{~g}$ de cenoura contém $852 \mu \mathrm{g}$ RAE (UNITED..., 2007), o que corresponde, em $24 \mathrm{~g}$ de cenoura, a $204 \mu \mathrm{g}$ RAE, sendo este teor inferior ao encontrado nas análises realizadas nesse estudo, o que sugere ser esse resultado a combinação dos alimentos no formulado.

Outro alimento que faz parte da composição dos formulados é a couve. De acordo com a literatura, a couve apresenta $5 \mu \mathrm{g}$ RAE. $100 \mathrm{~g}^{-1}$ (UNITED..., 2007), a $430 \mu \mathrm{g}$ RAE.100 g $\mathrm{g}^{-1}$ (MACHADO; CANNIATTI-BRAZACA; PIEDADE, 2006). Considerando que os formulados apresentem $20 \mathrm{~g}$ de couve em sua composição, esse valor representaria 1,2 ou 103,2 $\mu \mathrm{g}$, respectivamente, segundo a literatura USDA (UNITED..., 2007) e Machado, Canniatti-Brazaca e Piedade (2006).

Segundo USDA (UNITED..., 2007), a quantidade de RAE em 100 g de ovo é de $169 \mu \mathrm{g}$ RAE. A quantidade de ovo adicionada em cada formulado foi de $45 \mathrm{~g}$ no F4 e $30 \mathrm{~g}$ no F6, nos dois tipos de formulados líquidos e em pó. Esse valor corresponderia a 76 e 50,7 $\mu \mathrm{g}$ RAE, respectivamente.

Quando se compara a quantidade de teor de $\beta$-caroteno (Tabela 10) com os teores de ferro disponível (Tabela 7), verifica-se que o $\beta$-caroteno não é o único fator que influencia a disponibilidade de ferro. Analisando os formulados líquidos, encontraram-se os maiores valores de $\beta$-caroteno para o formulado F5, porém foi o que apresentou o menor teor de ferro disponível. Portanto confirma que outros fatores influenciam na disponibilidade do ferro. Machado, Canniatti-Brazaca e Piedade (2006), estudando mistura com ovos, cenoura e couve, constataram que houve aumento na disponibilidade de ferro, principalmente devido ao maior teor de $\beta$-caroteno, que influencia positivamente para esse aumento, considerando os alimentos utilizados no estudo.

Para Ramalho e Jorge (2008), alimentos com características antioxidantes como o $\beta$-caroteno, inibem os danos oxidativos das lipoproteínas de baixa densidade (colesterol LDL). Estes compostos atuam na preservação dos tecidos que revestem internamente o coração e os vasos sanguíneos e são importantes para a prevenção de trombose, aterosclerose e na manutenção da elasticidade vascular. Além das doenças do coração, o diabetes e as doenças gastrointestinais comuns entre os idosos, estão ligados à falta de vitamina $\mathrm{A}$. Estas doenças interferem na absorção, armazenamento, transformação e transporte deste nutriente no organismo, sendo fundamental seu consumo.

\subsection{Interações entre os nutrientes na disponibilidade de minerais e viscosidade}

Foram observadas as correlações entre o ferro dialisável e ácido fítico, fenólicos totais e betacaroteno (Tabela 11). O teste de correlação procurou analisar os comportamentos das análises de teor de ferro disponível em relação às análises de ácido fítico, fenólicos totais e $\beta$-caroteno, a fim de indicar as melhores alternativas dentre os diferentes formulados elaborados neste trabalho.

FL 1 e FP 1: arroz cozido, feijão cozido, proteína texturizada de soja, óleo de soja, cenoura e couve; FL 2 e FP 2: macarrão cozido, feijão cozido, proteína texturizada de soja, óleo de soja, cenoura e couve; FL 3 e FP 3: arroz cozido, leite em pó, proteína texturizada de soja, óleo de soja, cenoura e couve; FL 4 e FP 3: amido de milho cozido, ovo cozido, proteína texturizada de soja, óleo de soja, cenoura e couve; FL 5 e FP 5: amido de milho cozido, sardinha, proteína texturizada de soja, óleo de soja, cenoura e couve; FL 6 e FP 6: fubá cozido, ovo cozido, proteína texturizada de soja, óleo de soja, cenoura e couve.

Os dados da análise de regressão para o formulado líquido apresentaram correlação significativa e negativa para todos os formulados. A análise de regressão demonstrou que, para o formulado em pó, houve correlação significativa para todos os formulados verificando-se relação negativa apenas entre ferro dialisável $\times$ ácido fítico.

Na Figura 2, pode ser visualizado o que foi apresentado na Tabela 11, tanto para o ácido fítico quanto para o ferro dialisável, que seguiram o mesmo comportamento e correlação positiva.

O ácido fítico em condições naturais nos alimentos tem a capacidade de se associar a cátions ou proteínas devido à carga negativa da molécula. Em pH levemente ácido ou neutro, os seis grupamentos fosfato da molécula de ácido fítico expõem suas 12 cargas negativas, favorecendo a complexação direta ou indireta desta molécula com cátions bivalentes $(\mathrm{Ca}, \mathrm{Fe}, \mathrm{Zn}$, $\mathrm{Mg}, \mathrm{Cu}$ ), também com amido, proteínas e enzimas, podendo alterar a digestibilidade e absorção destes nutrientes (PALLAUF; RIMBACH, 1997).

A Figura 3 apresenta os teores de fenólicos totais sobre o efeito do ferro dialisável e a quantidade de ferro. Os valores de fenólicos aumentaram e a porcentagem de ferro dialisável diminui, apresentando correlação negativa significativa.

FL 1 e FP 1: arroz cozido, feijão cozido, proteína texturizada de soja, óleo de soja, cenoura e couve; FL 2 e FP 2: macarrão cozido, feijão cozido, proteína texturizada de soja, óleo de soja, cenoura e couve; FL 3 e FP 3: arroz cozido, leite em pó, proteína texturizada de soja, óleo de soja, cenoura e couve; FL 4 e FP 4: amido de milho cozido, ovo cozido, proteína texturizada de soja, óleo de soja, cenoura e couve; FL 5 e FP 5: amido de milho cozido, sardinha, proteína texturizada de soja, óleo de soja, cenoura e couve; FL 6 e FP 6: fubá cozido, ovo cozido, proteína texturizada de soja, óleo de soja, cenoura e couve.

Os formulados em pó apontam influência dos fenólicos na disponibilidade de ferro, na Figura 3. 
Tabela 11. Valores estatísticos de análise de regressão para teores de porcentagem de ferro dialisável e os demais nutrientes analisados em diferentes formulados.

\begin{tabular}{lccccc}
\hline \multicolumn{1}{c}{ Variáveis } & \multicolumn{2}{c}{ Valor de R } & & \multicolumn{2}{c}{ Valor de F } \\
\cline { 2 - 3 } \cline { 5 - 7 } & Formulado em pó & Formulado líquido & & Formulado em pó & Formulado líquido \\
\hline Ferro dialisável $\times$ Ácido fítico & 0,21601907 & 0,000186308 & & $1,102165^{\mathrm{s}}$ & $0,00074537^{\mathrm{s}}$ \\
Ferro dialisável $\times$ Fenólicos totais & 0,01751996 & 0,056034337 & & $0,071330^{\mathrm{s}}$ & $0,23744227^{\mathrm{s}}$ \\
Ferro dialisável $\times$ B-caroteno & 0,34949490 & 0,438557016 & & $0,5911809^{\mathrm{s}}$ & $0,66223637^{\mathrm{s}}$ \\
\hline
\end{tabular}

Notas: ns: correlação não significativa entre os formulados em nível de $5 \%$ de probabilidade; s: correlação significativa entre os formulados ao nível de $5 \%$ de probabilidade.

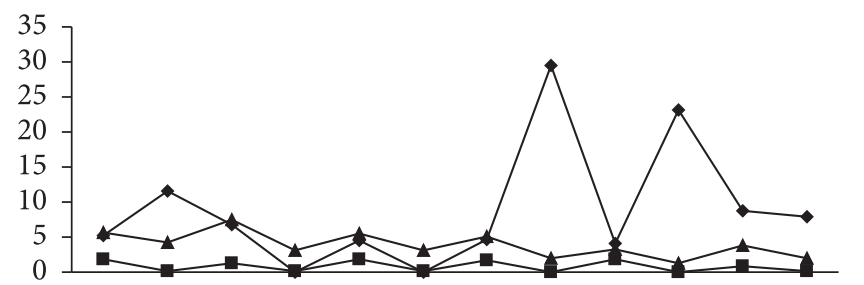

FL1 FP1 FL2 FP2 FL3 FP3 FL4 FP4 FL5 FP5 FL6 FP6

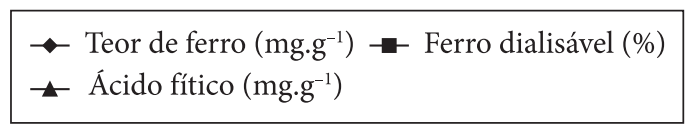

Figura 2. Efeito dos teores de ácido fítico sobre o ferro dialisável em diferentes formulados, FL (líquido) e FP (pó).

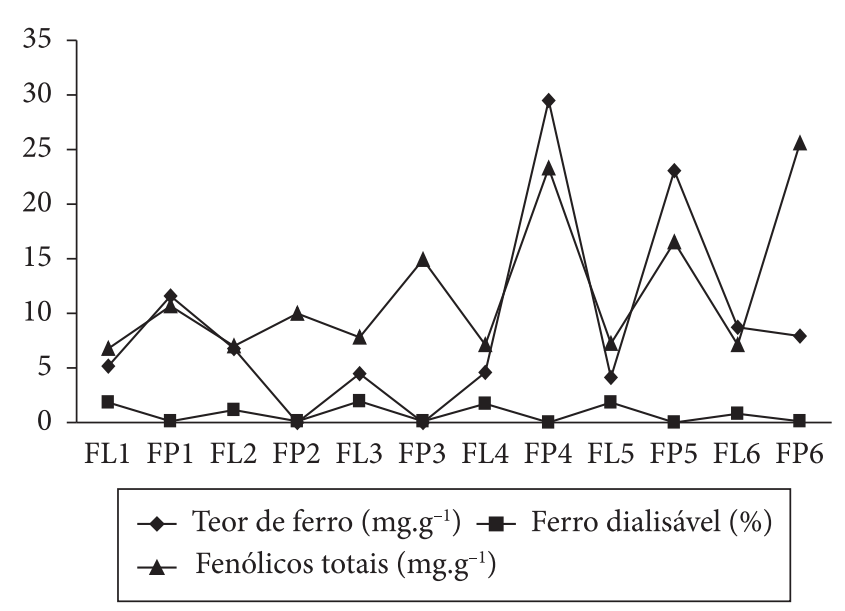

Figura 3. Efeito dos teores de fenólicos totais sobre o ferro dialisável em diferentes formulados, FL (líquido) e FP (pó).

Os formulados FP 6, FP 4 e FP 3 apresentaram os maiores teores de fenólicos totais e os menores teores de percentuais de ferro dialisável. Esses resultados podem evidenciar a influência do aquecimento na disponibilidade de ferro e o aumento nos teores de fenólicos totais.

Também foi observada correlação entre teor de $\beta$-caroteno e disponibilidade do ferro, sendo que quanto maior o teor de $\beta$-caroteno maior é a disponibilidade do ferro para o líquido, sendo o inverso para o formulado em pó (Tabela 11).

\subsection{Análises de custos dos formulados}

Após o levantamento das informações referentes aos preços dos produtos utilizados, foram estabelecidos valores médios para cada alimento e realizados os cálculos do custo aparente dos formulados.

O custo por $250 \mathrm{~mL}$ de cada formulado desenvolvido variou entre $\mathrm{R} \$ 0,19$ e $\mathrm{R} \$ 0,54$. Para F1, o custo aparente foi de R\$ 0,19; F2, R\$ 0,21; F3, R\$ 0,42; F4, R\$ 0,44; F5, R\$ 0,54; e para F6, R\$ 0,25.

Para comparação, foram selecionadas formulações industrializadas poliméricas e normocalóricas, normoproteicas e normolipídicas, tentando aproximar o máximo com os formulados desenvolvidos Para $250 \mathrm{~mL}$ de 3 diferentes marcas, os custos são de R\$ 5,46; R\$ 7,35; e R\$ 6,91. Considerando suplementos via oral padrão para as 3 diferentes marcas, os valores são de R\$ 8,01; R\$ 14,65; e R\$ 9,20.

O custo médio das fórmulas industrializadas poliméricas padrões foi de $\mathrm{R} \$ 6,57 \pm 0,98$, e para os suplementos via oral padrão foi de $\mathrm{R} \$ 10,62 \pm 3,54$. Esses valores são pelo menos 22 e 36 vezes superiores ao dos formulados desenvolvidos artesanalmente. Vale ser ressaltado que não foi considerada para a composição do custo total a inclusão da embalagem, comercialização, mão de obra, treinamento, padronização de procedimentos, área física específica, aquisição de equipamentos, utensílios e outros itens necessários para este fim, o que seria preciso para realizar uma avaliação mais conclusiva sobre valor.

Estudos realizados nas análises de custos de dietas artesanais mostraram que o custo médio das dietas desenvolvidas foi de $\mathrm{R} \$ 0,20 \pm 0,02$ e $\mathrm{R} \$ 0,27 \pm 0,01$ para cada $100 \mathrm{~mL}$, considerando só os gêneros alimentícios na composição deste custo (ATZINGAN; SILVA, 2007).

\section{Conclusões}

De acordo com os resultados, os alimentos analisados podem ser incluídos nas preparações de formulados para suplementação via enteral da população idosa: arroz, feijão, macarrão, leite em pó, sardinha, proteína texturizada de soja, amido de milho, ovo, óleo de soja, cenoura e couve-manteiga.

Os formulados apresentaram características diversificadas em suas composições centesimais; os formulados líquidos apresentaram teores superiores de carboidratos, proteínas, lipídios em relação aos formulados em pó, o que sugere que os formulados em pó tiveram maiores perdas de nutrientes devidas ao processo de cocção.

Apenas um dos formulados se caracterizou como dieta padrão F5 (formulado líquido), ou seja, normolipídica, normocalórica e normoproteica, de acordo com indicações da literatura. Outros formulados apresentaram característica 
hiperproteica, em relação aos lipídios houve diversificações, variando em hipolipídicos a hiperlipídicos.

No que diz respeito ao valor calórico total, os formulados apresentaram de 131 a $216 \mathrm{cal}$ por $250 \mathrm{~mL}$ de formulado Os formulados líquidos apresentaram valor calórico superior ao dos formulados em pó.

O teor de ferro apresentado pelos formulados em pó foi superior ao do formulado líquido, porém, estes apresentaram valores superiores de ferro disponível em relação aos formulados em pó, assim como o teor de $\beta$-caroteno.

A quantidade de ácido fitico, fenólicos totais estão associados à disponibilidade de ferro dos formulados, ficando mais evidentes nos formulados em pó. No caso, apresentaram valores superiores de antinutricionais que os formulados líquidos, principalmente nos teores de fenólicos totais.

Os formulados artesanais são viáveis economicamente e, em relação aos suplementos industrializados, apresentaram custos de 22 a 36 vezes menores, ficando em torno de $\mathrm{R} \$ 0,19$ a $\mathrm{R} \$ 0,54$ por $250 \mathrm{~mL}$ de formulado, e o F1 e F2, à base de arroz, feijão e macarrão, foram os mais econômicos, F5 apresentou o custo mais elevado, destacando a sua composição que continha proteína animal, a sardinha.

Os formulados líquidos apresentaram os melhores resultados nutricionais, além de viabilidade econômica, e podem ser recomendados para a suplementação enteral de idosos. Dentre estes, podem-se sugerir duas alternativas, conforme a necessidade clínica do idoso, considerando todos os aspectos nutricionais e físicos dos formulados. $\mathrm{O}$ formulado F3 destacou-se na disponibilidade de ferro, digestibilidade, viscosidade e gotejamento. $\mathrm{O}$ formulado $\mathrm{F} 4$ destacou-se na adequada distribuição do valor calórico total de macronutrientes, apresentando valores ideais para os idosos segundo as recomendações internacionais, além do maior valor calórico entre os formulados.

\section{Referências bibliográficas}

AKESON, W.R.; STAHMANN, M.A. A pepsin pancreatin digest index of protein quality evoluation. Journal of Nutrition, v. 83, p. 257-261, 1964.

ANGELO, P. M.; JORGE, N. Compostos fenólicos em alimentos - uma breve revisão. Revista do Instituto Adolfo Lutz, São Paulo, v. 66, n. 1, p. 1-9, 2007.

ARAÚJO, E. M.; MENEZES, H. C. Formulações com alimentos convencionais para nutrição enteral ou oral. Ciência e Tecnologia de Alimentos, Campinas, v. 26, n. 3, p. 533-538, 2006.

ASSOCIATION OF OFFICIAL ANALYTICAL CHEMISTS - AOAC. Official methods of analysis. $16^{\text {th }} \mathrm{ed}$. Washington, 2006. v. 2 .

ATZINGAN, M. C.; SILVA, M. E. M. P. Desenvolvimento e análise de custo de dietas enterais artesanais à base de hidrolisado protéico de carne. Revista Brasileira de Nutrição Clínica, v. 23, n. 3, p. 2310-213, 2007.

BAXTER, Y. C. et al. Critérios de decisão na seleção de dietas enterais. In: WAITZBERG, D. L. (Ed.). Nutrição oral, enteral e parenteral na prática clínica. 3. ed. São Paulo: Atheneu, 2000. Cap. 41, p. 659-676.
CAMPOS, F. M.; ROSADO, G. P. Novos fatores de conversão de carotenóides provitamínicos A1. Ciências Tecnologia Alimentos, Campinas, v. 25, n. 3, p. 571-578, 2005.

CARVALHO, P. R. N.; SILVA, M. G.; PARRA, E. B. Efeito da cocção sobre os teores de tiamina, riboflavina, piridoxina, niacina e ferro em macarrão enriquecido tipo espaguete. Coletânea do Instituto de Tecnologia de Alimentos, v. 27, n. 1/2, p. 57-60, 1997.

CÚNEO, F.; FARFAN, J. A.; CARRARO, F. Distribuição dos fitatos em farelo de arroz estabilizado e tratado com fitase exógena. Ciência e Tecnologia de Alimentos, v. 20, n. 1, p. 94-98, 2000.

DIETARY REFERENCE INTAKE - DRI. Dietary reference intake for energy, carbohydrates, fiber, fat, protein and amino acids (Macronutrients). Institute of Medicine -IOM, 2002. Disponível em: <http://www.nap.edu/openbook/0309085373/html/1.html>. Acesso em: 26 out. 2007.

DOMENE, S. M. A.; GALEAZZI, M. A. M. Prescrição e uso de formulados para nutrição enteral pelos serviços de nutrição hospitalares do município de Campinas. Revista de Nutrição da PUCCAMP, v. 10, n. 2, p. 158-168, 1997.

EMPRESA BRASILEIRA DE PESQUISA AGROPECUÁRIA EMBRAPA. O par perfeito: arroz e feijão. Disponível em $<\mathrm{http}: / /$ www.cnpaf.embrapa.br/parperfeito/index.htm>. Acesso em: 15 jan. 2008.

FERREIRA, E. R. A.; FIALHO, E. T.; TEIXEIRA, A. S. Avaliação da composição química e determinação de valores energéticos e equações de predição de alguns alimentos para suínos. Revista Brasileira de Zootecnia, v. 26, p. 514-523, 1997.

FIGUEIREDO, W. Assistência à saúde dos homens: um desafio para os serviços de atenção primária. Ciência e Saúde Coletiva, v. 10, n. 1, p. 105-109, 2005.

GARCIA-ARIAS, M. T. et al. Cooking freezing-reheating (CFR) of sardine (Sardina pilchardus) fillets: effect of different cooking and reheating procedures on the proximate and fatty acid compositions. Food Chemistry, v. 83, n. 3, p. 349-356, 2003.

GARCIA-CASAL, M. N. et al. Vitamin A and $\beta$-carotene can improve nonheme iron absorption from Rice, wheat and corn by humans. Journal of Nutrition, v. 128, n. 3, p. 646-650, 1998.

GRYNSPAN, F.; CHERYAN, M. Phytate-calcium interations with soy protein. Journal of the American Oil Chemists Society, v. 66, n. 1, p. 93-97, 1989.

GUZMÁN-MALDONADO, S. H.; ACOSTA-GALLEGO, J.; PAREDESLÓPEZ, O. Protein and mineral content of a novel collection of wild and weedy common bean (Phaseolus vulgaris L). Journal of the Science of Food and Agriculture, v. 80, n. 13, p. 1.874-1.881, 2000.

INSTITUTO BRASILEIRO DE GEOGRAFIA E ESTATÍSTICA - IBGE. Pesquisa de orçamentos familiares (POF) 2002-2003. Aquisição alimentar domiciliar per capita Brasil e Grandes Regiões. Rio de Janeiro, 2004.

INSTITUTO BRASILEIRO DE GEOGRAFIA E ESTATÍSTICA - IBGE. Censo demográfico 2000. Rio de Janeiro, 2002.

INSTITUTO DE ECONOMIA AGRÍCOLA - IEA. Índices de preços no Estado de São Paulo São Paulo, 2008. Disponível em : <http:// www.iea.sp.gov.br/out/banco/menu.php>. Acesso em: 04 abr. 2008.

KAWASHIMA, L. M.; VALENTE SOARES, L. M. Effect of blanching time on selective mineral elements extraction from the spinach substitute (Tetragonia expansa) commonly used in Brazil. Ciência e Tecnologia de Alimentos, v. 25, n. 3, p. 419-424, 2005.

LIMA, K. S. C.; LIMA, A. L. S.; FREITAS, L. C. Efeito de baixas doses de irradiação nos carotenoides majoritários em cenoura pronta 
para consumo. Ciência e Tecnologia de Alimentos, Campinas, v. 24, n. 2, p. 183-193, 2004.

MACHADO, F. M. V. F.; CANNIATTI-BRAZACA, S. G.; PIEDADE, S. M. S. Avaliação da disponibilidade de ferro em ovo, cenoura e couve e em suas misturas. Ciência e Tecnologia de Alimentos, v. 26, n. 3, p. 610-618, 2006.

MALACRIDA, C. R.; MOTTA, S. Total phenolics and anthocyanins in grape juice. Ciência e Tecnologia de Alimentos, v. 25, n. 4, 2005. Disponível em: <http://www.scielo.br/scielo.php?script $=$ sci_ arttext\&pid=S0101-20612005000400006\&lng=en\&nrm=iso $>$. Acesso em: 03 abr. 2008.

MARTINEZ, A. P. C. et al. Efeitos da germinação da soja sobre a composição química do grão. In: SIMPÓSIO INTERNACIONAL DE INICIAÇÃO CIENTÍFICA DA UNIVERSIDADE DE SÃO PAULO, 15., 2007, Ribeirão Preto. Anais...

MARTINI, F. C. C. Comparação entre a disponibilidade de ferro na presença de vitamina $A$ e beta-caroteno em alimentos e medicamentos. Dissertação (Mestrado em Ciência e Tecnologia de Alimentos) - Escola Superior de Agricultura Luiz de Queiroz, Universidade de São Paulo, Piracicaba, 2002.

MICROSOFT. Microsoft Office Excel 2003. São Paulo, 2003. 1 CDROM.

MINAZZI-RODRIGUES, R. S.; PENTEADO, M. V. C. Carotenóides com atividade pró-vitaminica A em hortaliças folhosas. Revista de Farmácia e Bioquímica da Universidade de São Paulo, v. 25, n. 1, p. 39-52, 1989.

MOREIRA, M. A. Medidas caseiras no preparo de alimentos. 2. ed. Goiânia: AB, 2002. 144 p.

MOURA, N. C.; CANNIATTI-BRAZACA, S. G. Evaluation of iron availabilty of the common bean in comparson with bovine meat. Ciência e Tecnologia de Alimentos, v. 26, n. 2, 2006. Disponível em: <http://www.scielo.br/scielo.php?script=sci_arttext\&pid=S010 $10612006000200007 \& \operatorname{lng}=$ en\&nrm=iso $>$. Acesso em: 04 abr. 2008.

NUNES, C. S.; BAPTISTA, A. C. Implicações da reação de Maillard nos alimentos e nos sistemas biológicos. Revista Portuguesa de Ciências Veterinárias, v. 96, n. 538, p. 53-59, 2001.

PALLAUF, J.; RIMBACH, G. Nutritional significance of phytic acid and phytate. Achieve Animal Nutrition, Logan, USA, v. 50, n. 4, p. 301-310, 1997.

PIMENTEL-GOMES, F. Curso de estatística experimental. 10. ed. São Paulo: Nobel, 1982. 468 p.

PINHEIRO, A. B. V. et al. Tabela para avaliação de consumo alimentar em medidas caseiras. 4. ed. São Paulo: Atheneu, 2002. 75 p.

PINHEIRO-SANT'ANA, H. M. et al. Avaliação de carotenóides totais, alfa e beta-caroteno em cenoura (Daucus carota L.) durante processamento a nível doméstico. Ciência Tecnologia Alimentos, v. 18, n. 1, 1998. Disponível em: <http://www.scielo.br/scielo. php?script=sci_arttext\&pid=S0101-20611998000100009\&lng=pt \&nrm=iso >. Acesso em: 14 abr. 2008.

PIRES, C. V. et al. Qualidade nutricional e escore químico de aminoácidos de diferentes fontes protéicas. Ciência Tecnologia Alimentos, v. 26, n. 1, p. 179-187, 2006.

POTTER, N. N.; HOTCHKIN, J. H. Ciencia de los alimentos. 5. ed. Zaragoza: Acribia, 1995. 667 p.
RAMALHO, V. C.; JORGE, N. Acción antioxidante Del extracto de Romero em El aceite de soja sometido a termoxidación. Grasas y Aceites, v. 59, n. 2, p. 128-131, 2008.

RIBEIRO, M. L. L.; IDA, E. I.; OLIVEIRA, M. C. N. Efeito da germinação de soja cv. Br-13 e paraná sobre ácido fítico, fósforo total e inibidores de tripsinal. Pesquisa Agropecuária Brasileira, v. 34, n. 1, p. 31-36, 1999.

SARRUGE, J. R.; HAAG, H. P. Análises químicas em plantas. Piracicaba: USP/ESALQ, 1974. 56 p.

SGARBIERI, V. C. Proteínas em alimentos protéicos: propriedades, degradações e modificações. São Paulo: Varela, 1996. 517 p.

SILVA M. R.; SILVA, M. A. A. P. Aspectos nutricionais de fitatos e taninos. Revista Nutrição, Campinas, v. 12, n. 1, p. 5-19, 1999.

SOUZA, E. L. e al. Fatores antinutricionais: elementos de interferência sobre a biodisponibilidade de nutrientes. Higiene alimentar, v. 19, n. 131, p. 19-23, 2005.

STATISTICAL ANALYSIS SYSTEM INSTITUTE - SAS. Sas/Qc software: usage and reference $2^{\text {th }}$ ed. Cary, 1996. $2 \mathrm{v}$.

SWAIN, T.; HILLIS, W. E. J. Science. Food Agriculture, Helsinki, v. 10, p. $63-68,1959$.

TOLEDO, T. C. F. et al. Composição, digestibilidade protéica e desaminação em cultivares brasileiras de soja submetidas à radiação gama. Ciência e Tecnologia de Alimentos, v. 27, n. 4, p. 812-815, 2007.

TOLEDO, T. C. F.; CANNIATTI-BRAZACA, S. G. Avaliação química e nutricional do feijão carioca (Phaseolus vulgaris L.) cozido por diferentes métodos. Ciência e Tecnologia de Alimentos, v. 28, n. 2, p. 355-360, 2008.

UCHÔA, E.; FIRMO, J. O.; LIMA-COSTA, M. F. Envelhecimento e saúde:experiência e construção cultural. In: MINAYO, M.C.S.; COIMBRA Jr.; C.E.A. (Org.) Antropologia, saúde e envelhecimento. Rio de Janeiro: Editora Fiocruz, 2002. p. 25-50.

UNIVERSIDADE DE CAMPINAS - UNICAMP. Tabela brasileira de composição de alimentos - TACO. 2. ed. Campinas: NepaUnicamp, 2006. Disponivel em: <http://www.unicamp.br/nepa/ taco/contar/taco_versao2.pdf $>$. Acesso em: 22 fev. 2008.

UNIVERSIDADE DE SÃO PAULO - USP. Tabela brasileira de composição de alimentos. São Paulo, 2004. Versão 4.1. Disponivel em: <http://www.fcf.usp.br/tabela>. Acesso em: 22 fev. 2008.

UNITED STATES DEPARTAMENT OF AGRICULTURE - USDA. Departament of Agriculture. National nutrient database for Standard reference. Release 20. 2007. Disponível em: <http://www. nal.usda.gov/fnic/foodcomp./caj-bin/list_nut_edit.p.1>. Acesso em: 15 jan. 2008.

WASSIMI, N. N.; HOSFIELD, G. L.; UEBERSAX, M. A. Combining ability of tannin content and protein characteristics of raw and cooked dry beans. Crop Science, v. 28, n. 3, p. 452-458, 1988.

WHITTAKER, P.; FOX, M. R.S.; FORBES, A. L. In vitro prediction of iron bioavailability for food fortification. Nutrition Reporter International, v. 39, n. 6, p. 1205-1215, 1989.

YAMADA, L. T. P. et al. Composição química e conteúdo de ferro solúvel em soja (Glycine max (L.) Merrill). Ciência Agrotecnologia, v. 27, n. 2, p. 406-413, 2003. 